PPPL- -2511

DE88 009346

\title{
Profile Correction to Electron Temperature and Enhancement Factor in Soft X-ray Pulse-Height-Analysis Measurements in Tokamaks
}

\author{
S. SESNIC, M. DIESSO, K. HILL, A. HOLLAND \\ Princeton University, Plasma Physics Laboratory, P.O.Box 451, Princeton, N.J. 08543 \\ and F. POHL \\ Max-Planck Institut für Plasmaphysik, 8046-Garching, F.R. Germany
}

\begin{abstract}
Because soft $x$-ray pulse-height-analysis (PHA) spectra contain chordal information, the electron temperature and the radiation intensity (enhancement factor) measurements do "ot represent the local values. Assuming that the profile Ansatz for the electron temperature a.d density is of the form $n_{e o}\left(I-(r / a)^{2}\right)^{\alpha}$ and $k T_{e o}\left[1-(r / a)^{2}\right)^{\beta}$, we obtain the correction factors $f$ the electron temperature and the enhancement factor as a function of the profile coefficients $\alpha$ an: $\beta$ and the energy at which the evaluation was made. The corrected values of the temperature is typically between 1 so $10 \%$ higher than the values derived from the raw chordat spectra. We also correct the measured radiation intensity for the profile effects. Finally, the spectrum distortion due to pulse pile-up effects is evaluated. A set of curves is given from which the distortion of the spectrum can be obtained, if the electron temperature, the Be or Al filter thickness, and the electronic parameters of the acquisition system are known.
\end{abstract}

\section{INTRODUCTION}

The pulse-height-analysis (PHA) system ${ }^{1-3}$ measures the soft $x$-ray spectrum along the line of sight. Because this is the line of sight measurement, the measured spectrum is an overlay of spectra coming from regions of different electron temperatures and densities and, therefore, the slope of the measured spectrum representing the electron temperature does not exhibit a unique value. Since the measured temperature is not a correct peak temperature, it is of interest to know how to estimate the error in measurement or even how to correct this value. This error depends very strongly on the electron temperature and density profiles and it is important to find the functional dependence of the correction factor on the profile parameters. These profile parameters can vary in today's tokamaks very much, because they depend on the heating

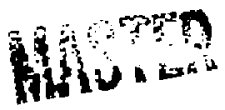


method (neutral beam heating, ICRH, ECH, etc.) and on the fuelling method (gas, pellets, neutral beam). Both heating and fuelling can be carried out either in the center or at the edge of the plasma, resulting in large differences in the temperature and density profiles.

One way of finding the correct temperatures is to make a set of measurements along different lines of sight and then to make an Abel inversion. ${ }^{4}$ In the case where one has only one or only a few line of sight measurements, one cannot make the Abel inversion. In this case one has to find other ways to correct the measured values. In this paper we are concerned with this other case, where there are only a few lines of sight measurements. To obtain the correct values for the electron temperature from a single line of sight measurement one has either to know the form of the electron temperature and density profiles or at least know these forms approximately. Our method is based on such an assumption that we know these profiles at least to a certain degree. The profile forms, for example, could be obtained from laser scattering. In this case, since the correct temperature is presumably found from the laser scattering experiment, the temperature correction per se would not be so important. However, the PHA measurement also allows one to find the radiation enhancement coefficient $\zeta$ from which one can deduce the local $Z_{\text {eff }}$ values $^{1-4}$ at each line of sight position. (The enhancement coefficient $\zeta$ is defined as a ratio of the measured continuum to a pure hydrogen bremsstrahlung. It is normally always larger than I due to the presence of impurities in the real plasma, which cause, on one hand, an increase in bremsstrahlung radiation and, on the other hand, an appearance of a strong recombination radiation.) The accuracy of the $\zeta$ or $Z_{\text {eff }}$ values depends on the accuracy of the electron temperature value. Therefore, even if we know the electron temperature from some other measurement, we still need to correct the PHA electron temperature and the enhancement coefficient in order to obtain the corrected local $Z_{\text {eff }}$ and corrected local impurity densities obtained from the PHA line radiation and $\zeta$ measurements.

Another distortion of the spectra is caused by pulse pile-up effects. If two or more photons arrive within a time period shorter than the time needed for the electronics to recognize a single pulse, the electronics system will register these two or more photons as a single photon of the energy nearly equal to the sum of energies of the single photons. This distorts both the electron temperature and enhancement coefficient measurement. Various aspects of this problem have been handled by differen: authors. ${ }^{5-7}$ This paper presents only the corrections to the enhancement coefficient as a function of the electron temperature and the filter material and thickness, although the distortion of the electron temperature is also implied in the discussion.

In part I we discuss the corrections to the electron temperature and enhancement coefficient for various profiles and photon energies. In part II we discuss the corrections to the enhancement coefficient for different filter thicknesses and electron temperatures. 


\section{ELECTRON TEMPERATURE AND ENHANCEMENT COEFFICIENT CORRECTION}

In the case of a pure continuum radiation without line radiation, seting the Gaunt factor equal to 1 and with the density, electron temperature, and enhancement coefficient profiles represented as $n_{e}(z), k T_{e}(z)$, and $\zeta(z)$ the measured radiation spectrum can be described by the theoretictil expression 1

$$
S(p ; E)=2 A \int^{L} \zeta(z) n_{e}{ }^{2}(z) \exp \left[-E / k \tau_{e}(z)\right] /\left[k T_{e}{ }^{1 / 2}(z)\right] d z
$$

where $A$ is the radiation constant, $E$ is the photon energy, and $z$ is the position along the line of sight, L. For the purpose of demonstrating this correction method we assume a circular plasma and approximate the plasma profiles by $n_{e}(\rho)=n_{e 0}\left(1-\rho^{2}\right)^{\alpha}, k T_{e}=k T_{e o}\left(1-\rho^{2}\right)^{\beta}$ and, tor simplicity, assume $\zeta(\rho)=\zeta_{0}$. Here we introduce $\rho=\tau / a$, where $\tau$ is the minor radius and a is the plasma size. We also introduce the normalized tangency radius $p=r_{t} / a$, with $r_{t}$ being the minimum distance berween the line of sight and the center of the plasma. In general, we are interested in the off-axis measurements of $k T_{e}(p)$ and not $k T_{e 0}$ (they, of course, coincide if $p=$ $0)$. Therefore, $k T_{e}(p)=k T_{e}(p)\left[\left(1-p^{2}\right) /\left(1-p^{2}\right)\right]^{\beta}$ and $n_{e}(p)=n_{e}(p)\left[\left(1-p^{2}\right) /\left(1-p^{2}\right)\right]^{\alpha}$ should describe well the profiles in the vicinity of $\rho=p$.

The measured spectrum, which should be equal to the theoretical spectrum in expression (1), can be approximated by

$$
S_{m}(E)=\exp \left(a / E+b+c E+d E^{2}\right)
$$

where $a, b, c$, and $d$ are constants obtained by fitting the measured spectrum. If we simplify the fitting and set $a=d=0$ and retain $b$ and $c$ only, the following arguments and the correction formulas still apply. The (incorrect) measured temperature $T_{m}$ can be obtained from the fitced measured spectrum simply by finding the negative inverse of the slope of the natural logarithm of $S_{m}$ at the energy $E$

$$
T_{m}(E)=-1 /\left(d \ln S_{m} / d E\right)=-1 /\left(-a / E^{2}+c+2 d E\right)
$$


This electron temperature is not the correct temperature. We would, therefore, like to find the correction factor $T_{c} T_{m}$, where $T_{c}=k T_{e}(p)$ is the correct value of the temperature at the tangency radius $\mathrm{p}$. Note also that this measured temperature depends on the energy at which it was evaluated from the slope of the measured spectrum. For the purpose of finding the correct temperature in a more general form we define the normalized effective plasma thickness at $p=p$ :

$$
I(p)=\langle L\rangle / 2 a=S(p) /\left\{A \zeta(p) n_{e}{ }^{2}(p) \exp \left[-E / k T_{e}(p)\right] /\left[k T_{e}^{1 / 2}(p)\right]\right\}
$$

The effective thickness is the thickness of an equivalent homogeneous plasma of temperature $k T_{e}(p)$ and density $n_{e}(p)$ (plasma values at tangency radius) such that its radiation intensity at energy $E$ is equal to that of the measured spectrum at the same energy $E$. It is obvious from the expression (4) that the effective thickness $<L>$ is not a constant but that it varies with energy.

By taking the natural logarithm of $1(p)$ and defining it as $\Lambda=\ln l(p)$, by nomalizing energy in terms of the incorrect electron temperature $T_{m}, \varepsilon=E / T_{m}$, and by utilizing expressions (1), (2), and (3) in (4), we obtain for the correction factor

$$
T_{c} T_{m}=(1+d A / d \varepsilon)^{-1}
$$

To determine the ratio of the corrected enhancement coefficient $\zeta_{\varnothing}$ to the measured coefficient $\zeta_{m}$ one also must have the correct and measured values of the spectrum intercepts $S_{o c}$ and $S_{o m}$. The intercept is defined as the value of the spectrum $S$ at $E=0$. Since the intercept value is $S_{0}=$ $S(E) \exp \left(E / k T_{e}\right)$, where $S(E)$ is the value of the either correct or measured spectrum at the energy $E$, one can show that $S_{o c} / S_{o m}=\exp (\varepsilon \mathrm{dN} / \varepsilon)$. The measured and corrected values of the enhancement coefficient in terms of the corresponding intercept values are given by $\zeta_{\mathrm{m}}=$ $S_{o m} T_{m}^{1 / 2} /\left[A 2 a\left(1-p^{2}\right)^{1 / 2} n_{e}{ }^{2}(p)\right]$ and $\zeta_{c}=S_{o c} T_{c}^{1 / 2} /\left[A<L>n_{e}{ }^{2}(p)\right]$, where $A$ is again the appropriate radiation constant. Note that the measured enhancement coefficient $\zeta_{\mathrm{m}}$ is obtained by averaging the radiation intensity over the pertinent line of sight length $2 a\left(1-p^{2}\right)^{1 / 2}$. 
The correction factor for the enhancement coefficient now becomes

$$
\zeta_{d} / \zeta_{\mathrm{m}}=\exp (\varepsilon \mathrm{d} N / \mathrm{d} \varepsilon)\left(1-\mathrm{p}^{2}\right)^{1 / 2} /\left[1(1+\mathrm{d} \Lambda / \mathrm{d} \varepsilon)^{1 / 2}\right] .
$$

The expressions (4), (5), and (6) are valid for any type of plasma form and profile, not only for the circular plasma assumed above. The expressions (5) and (6) were numerically evaluated for the profiles with $\alpha$ and $\beta$ parameters and the results are shown in Figs. 1 to 10 for normalized energies $\varepsilon=1.0,2.5,5.0,7.5$, and 10.0. The error in electron temperature, incurred by taking simply the slope of the measured spectrum for the electron temperature, can be very large for small normalized energy: as high as $70 \%$ for the profiles with lowest $\alpha$ 's and highest $\beta$ 's. With the increase of normalized energy this error becomes smaller and smaller, e.g., at $\varepsilon=10$ and $\beta=$ 2 the error in electron temperature decreases to less than $5 \%\left(T_{c} / T_{m}=1.05\right)$. The error in temperature increases also with $\beta$, i.e., with a more peaked temperature profile. On the other hand, the enror in temperature increases with decreased $\alpha$, i.e., with a broader density profile.

The error in $\zeta$ estimates, i.e., the correction factor $\zeta_{c} / \zeta_{\mu}$, increases with both $\alpha$ and $\beta$ (profile peakedness). The $\zeta_{c} / \zeta_{m}$ values are normally high because of the definition of $\zeta_{m}$ - the measured radiation is averaged over the full length of the radiation path, in this case over $2 \mathrm{a}$.

The dependence of the error (correction factor) on the normalized energy, i.e., on the energy in the spectrum, where the measurement is done, is shown in Figs. 11 to 16. The higher the normalized energy (the further in the spectrum we take the measurement), the smaller the error in electron temperarure, which is something we expected. At the same time the error in the $\zeta$ estimate is larger. The error in both $\mathrm{kT}_{\mathrm{e}}$ and $\zeta$ estimates increases with $\beta$ (electron temperature peakedness), which is, of course, the same dependence as seen in Figs. 1 to 10 . The error in $k T_{e}$, however, slightly decreases with $\alpha$. The enror in $\zeta$ with increasing $\alpha$ changes even less, but instead of decteasing, it increases.

The errors in estimating the electron temperature and enhancement coefficient depend on the position of the line of sight, p. This is shown in Figs. 17 and 18, where the correction factors $T_{c} / T_{m}$ are presented as a function of $p$ and $\beta$, but where $\alpha$ and $\varepsilon$ are kept constant. The electron temperature correction factor $T_{c} / T_{m}$ is not a very strong function of $p$, but the enhancement coefficient correction factor $\zeta_{c} / \zeta_{\mathrm{m}}$ increases very much for $p$ 's close to 1 , i.e., near the edge of the plasma. This enhancement coefficient correction factor increases also very strongly with the increasing peakedness ( $\beta$ ) or temperature gradient at the edge of the plasma . 


\section{PULSE PILE-UP CORRECTION}

A PHA system usually has two electronic circuits to process the single pulses: a fast one and a slow one. The fast circuit recognizes and counts the single pulses. The minimum time interval between two pulses for the fast system to recognize them as single pulses is $\tau$. The slow electronic circuit processes the single pulses and the processing time $\tau_{\mathrm{s}}$ is much longer than $\tau$. The pulses arriving within a time interval longer than $\tau_{\mathrm{s}}$ are processed. Those pulses that arrive within a time interval shorter than $\tau_{s}$ but longer than $\tau$ are recognized as double puises, which would, if processed, distort the spectrum, and are, therefore, rejected. The pulses coming within the time interval shorter than $\tau$ are not recognized as double, triple, etc. pulses, but as a single pulse equal in energy to their sum. They, therefore,will be processed and will distort the measured spectrum. The purpose of this part of the paper is to find the distortion of the spectrum due to double pulses and to the presence of an $x$-ray filter. The triple and higher order pulses? are not discussed in this paper.

A measured soft $x$-ray spectrum can be represented in terms of the normalized energy $\varepsilon=E / k T_{e}$, the transmission function of the $x$-ray filter $F(E)=\exp [-\mu(E) d]$, and the photon count rare $\mathrm{N}_{\mathrm{c}}$ (photons per second) as

$$
S(\varepsilon)=N_{c}\left\{\int_{0}^{\infty} F(E)[\exp (-\varepsilon) / \varepsilon] d \varepsilon\right\}^{-1} F(E) \exp (-E) / \varepsilon
$$

where $\mu(E)$ is the total $x$-ray photon attenuation cross section of a given filter material and $d$ is the thickness of the filter. The attenuarion cross section can be mostly approximated by a function $\mu(E)=A E^{-B}$, where $A$ and $B$ are constants of the material with $B$ having a value close to 3 . Considering the coincidence of only two pulses during the time interval $\tau$, it has been show 5 that the double pulse spectrum can be described by the convolution integral

$$
\widetilde{S}(\varepsilon)=\tau / 4 \int_{0}^{\infty} S\left(\varepsilon^{\prime}\right) S\left(\varepsilon-\varepsilon^{\prime}\right) d \varepsilon^{\prime}
$$


We assume here that the pulses are of rectangular shape with a width of $\tau$. A better approximation for the shape of the pulses would be to take a triangular pulse $^{6}$ of the same width $\tau$.

Defining a nomalized ratio of the double pulse spectrum to the original spectrum as $R_{N}=4 \tilde{S}(\varepsilon) /\left[\tau N_{c} S(\varepsilon)\right]$, we obtain for the normalized ratio

$$
\begin{gathered}
R_{N}(\varepsilon)=\varepsilon \exp \left[A d\left(\varepsilon k T_{e}\right)^{-B}\right]\left\{\int_{0}^{\infty} \exp \left[-A d\left(\varepsilon k T_{e}\right)^{-B}\right] \exp (-\varepsilon) / \varepsilon d \varepsilon\right\}^{-1} * \\
* \int_{0}^{\infty} \exp \left[-A d k T_{e}^{-B}\left[\left(\varepsilon^{\prime}\right)^{-B}+\left(\varepsilon-\varepsilon^{\prime}\right)^{-B}\right]\right]\left[\varepsilon^{\prime}\left(\varepsilon-\varepsilon^{\prime}\right)\right]^{-1} d \varepsilon^{\prime}
\end{gathered}
$$

The parameters in this expression are the filter material constants $A$ and $B$, the electron temperature $\mathrm{kT}_{e}$, and the variable is the normalized energy $\varepsilon$. This expression has been numerically evaluated. The numerical results for the beryllium filter are shown in Figs. 19 to 21 and for the aluminum filter in Figs. 22 and 23. Since the expression (9) depends on several parameters and variables, we define a new parameter $\mathrm{D}=\mathrm{Ad}\left(\mathrm{kT}_{\mathrm{e}}\right)^{-\mathrm{B}}$, which characterizes the filter function not in terms of photon energy but in terms of electron temperature. The expression (9) then depends only on this new parameter $D$ and on the nomalized energy $\varepsilon$. Figures 19 and 22 then show the dependence of this parameter $D$ for the given filter material on the electron temperature. In Figs. 20, 21, and 22 the normalized double spectrum ratio $R_{N}$ is shown as a function of the normalized energy with $D$ as a parameter.

The plots in Figs. 19 to 23 are used to find the spectral distortion for a measured spectrum at any energy $\varepsilon$. Knowing the electron temperature at least approximately and knowing the filter thickness, we find in Fig. 19 or 22 the value of the parameter $D$. With this value of $D$ we go to Fig. 20,21 , or 23 and find the ratio $R_{N}$ at any normalized energy $\varepsilon$. Knowing the pulse pile-up constant $\tau$ of the electronic circuit and the measured count rate $\mathrm{N}_{c}$, we can obtain the relative spectral distortion $\tilde{S}(\varepsilon) / S(\varepsilon)=R_{N} \tau N_{c} / 4$, where again $S(\varepsilon)$ is the undistorted spectrum. From the value of the spectral distortion we can easily correct the value of the enhancement coefficient.

\section{ACKNOWLEDGMENT}

This work has been supported by U.S. DoE Contract No. DE-AC02-76-CHO-3073. 


\section{REFERENCES}

'S. von Goeler, W. Stodiek, H. Eubank, H. Fishman, S. Grebenshchikov, and E.Hinnov, Nucl. Fusion 15, 301 (1975).

${ }^{2}$ S. Sesnic, Max-Planck Instirut fiir Plasmaphysik Repor, IPP III/2, (1976).

${ }^{3}$ Equipe TFR, Nucl. Fusion 17, 2 (1977).

${ }^{4}$ E. H. Silver, M. Bitter, K. Brau, D. Eames, A. Greenberger, K. W. Hill, D. M. Mead, W. Roney, N. R. Sauthoff, and S. von Goeler, Rev. Sci. Instrum. 53, 1 I98 (1982).

${ }^{5}$ S. von Goeler, W. Stodiek, H. Eubank, Y. Sun. P. Thompson, and S. Slusky, Princeton Plasma Physics Laboratory Report No. MATT-1060, (1975).

${ }^{6}$ G. R. Dyer, G. H. Nielson, and G. G. Kelley, Nucl. Instrum. Methods 161, 365 (1979).

${ }^{7}$ F. H. Tenney, Nucl. Instrum. Methods 219, 165 (1984). 


\section{FIGURE CAPTIONS}

FIG. 1. Electron temperature correction factor $T_{\mathrm{c}} \pi_{\mathrm{m}}$ as a function of the electron density and temperature profile parameters $\alpha$ and $\beta$ and for the normalized energy $\varepsilon=1$ and $p=0$.

Fig. 2. Electron temperature correction factor $T_{c} / T_{m}$ for $\varepsilon=2.5$ and $p=0$.

Fig. 3. Electron temperature correction factor $T_{c} / T_{m}$ for $\varepsilon=5$ and $p=0$.

Fig. 4. Electron temperature correction factor $T_{c} / T_{m}$ for $\varepsilon=7.5$ and $p=0$.

Fig. 5. Electron temperature correction factor $T_{c} / T_{m}$ for $\varepsilon=10$ and $p=0$

Fig. 6. Enhancement coefficient correction factor $\zeta_{\mathrm{c}} / \zeta_{\mathrm{m}}$ as a function of the electron density and temperature profile parameters $\alpha$ and $\beta$ and for the normalized energy $\varepsilon=1$ and $p=0$.

Fig. 7. Enhancement coefficient correction factor $\zeta_{c} / \zeta_{\mathrm{m}}$ for $\varepsilon=2.5$ and $\mathrm{p}=0$.

Fig. 8. Enhancement coefficient correction factor $\zeta_{c} / \zeta_{\mathrm{m}}$ for $\varepsilon=5$ and $\mathrm{p}=0$.

Fig. 9. Entiancement coefficient correction factor $\zeta_{c} / \zeta_{m}$ for $\varepsilon=7.5$ and $p=0$.

Fig. 10. Enhancement coefficient correction factor $\zeta_{c} / \zeta_{m}$ for $\varepsilon=10$ and $p=0$.

Fig. 11. Electron temperature correction factor $T_{c} / T_{m}$ as a funcrion of the nornalized energy $\varepsilon$ and electron temperanure profile parameter $\beta$ and for $\alpha=0.5$ and $p=0$.

Fig. 12. Electron temperanure correction factor $T_{c} / T_{m}$ for $\alpha=1$ and $p=0$.

Fig. 13. Electron temperature correction factor $T_{c} / T_{m}$ for $\alpha=2$ and $p=0$.

Fig. 14. Enhancement coefficient correction factor $\zeta_{c} / \zeta_{\mathrm{m}}$ as a function of the normalized energy $\varepsilon$ and electron temperature profile parameter $\beta$ and for $\alpha=0.5$ and $p=0$. 
Fig. 15. Enhancement coefficient correction factor $\zeta_{c} / \zeta_{m}$ for $\alpha=1$ and $\mathrm{p}=0$.

Fig. 16. Enhancement coefficient correction factor $\zeta_{c} / \zeta_{m}$ for $\alpha=2$ and $p=0$.

Fig. 17. Dependence of the electron temperature correction factor $T_{c} / T_{m}$ on the sight line position $\mathrm{p}$ and electron temperature profile coefficient $\beta$ but for constant $\alpha$ and $\varepsilon$.

Fig. 18. Dependence of the enhancement coefficient correction factor $\zeta_{c} / \zeta_{m}$ on $p$ and $\beta$ with $\alpha$ and $\varepsilon$ being constant.

Fig. 19. Filter parameter $\mathrm{D}=\mathrm{AdkT} \mathrm{e}^{-\mathrm{B}}$ for beryllium foil as a function of the electron temperanure $k T_{\mathrm{e}}$ and filter thickness $\mathrm{d}$.

Fig. 20. Normalized double pulse spectrum $R_{N}$ as a function of the normalized energy $\varepsilon$ and the filter parameter $\mathrm{D}$ and for the beryllium foil.

Fig. 21. Normalized double pulse spectrum $R_{N}$ for beryllium and for lower values of $R_{N}$ and electron temperature $\mathrm{kT}_{\mathrm{e}}$.

Fig. 22. Filter parameter $D$ for aluminum foil as a function of the electron temperature $k T_{e}$ and filter thickness d.

Fig. 23. Normalized double pulse spectrum $\mathbf{R}_{\mathrm{N}}$ for aluminum. 


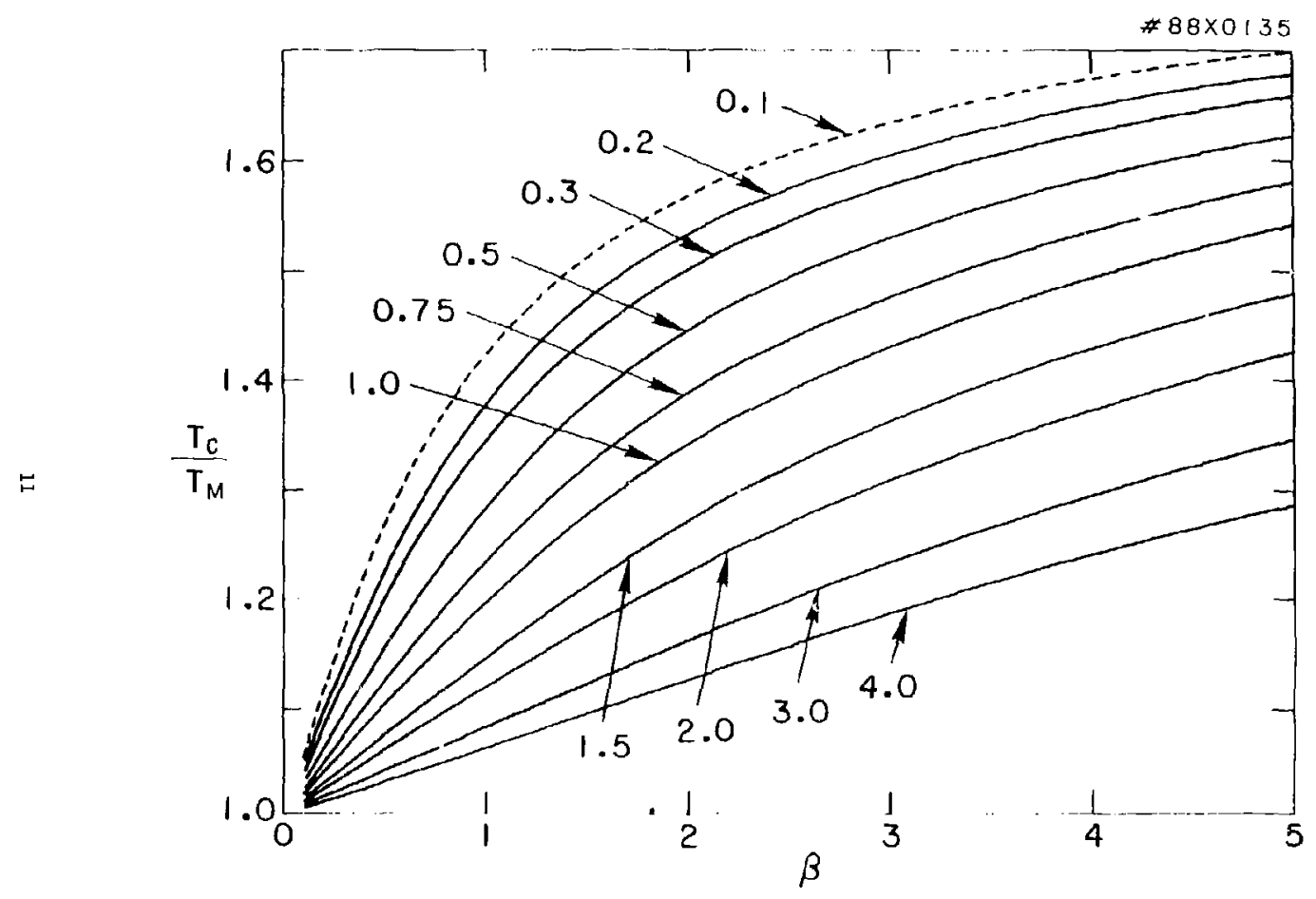


\#88x0136

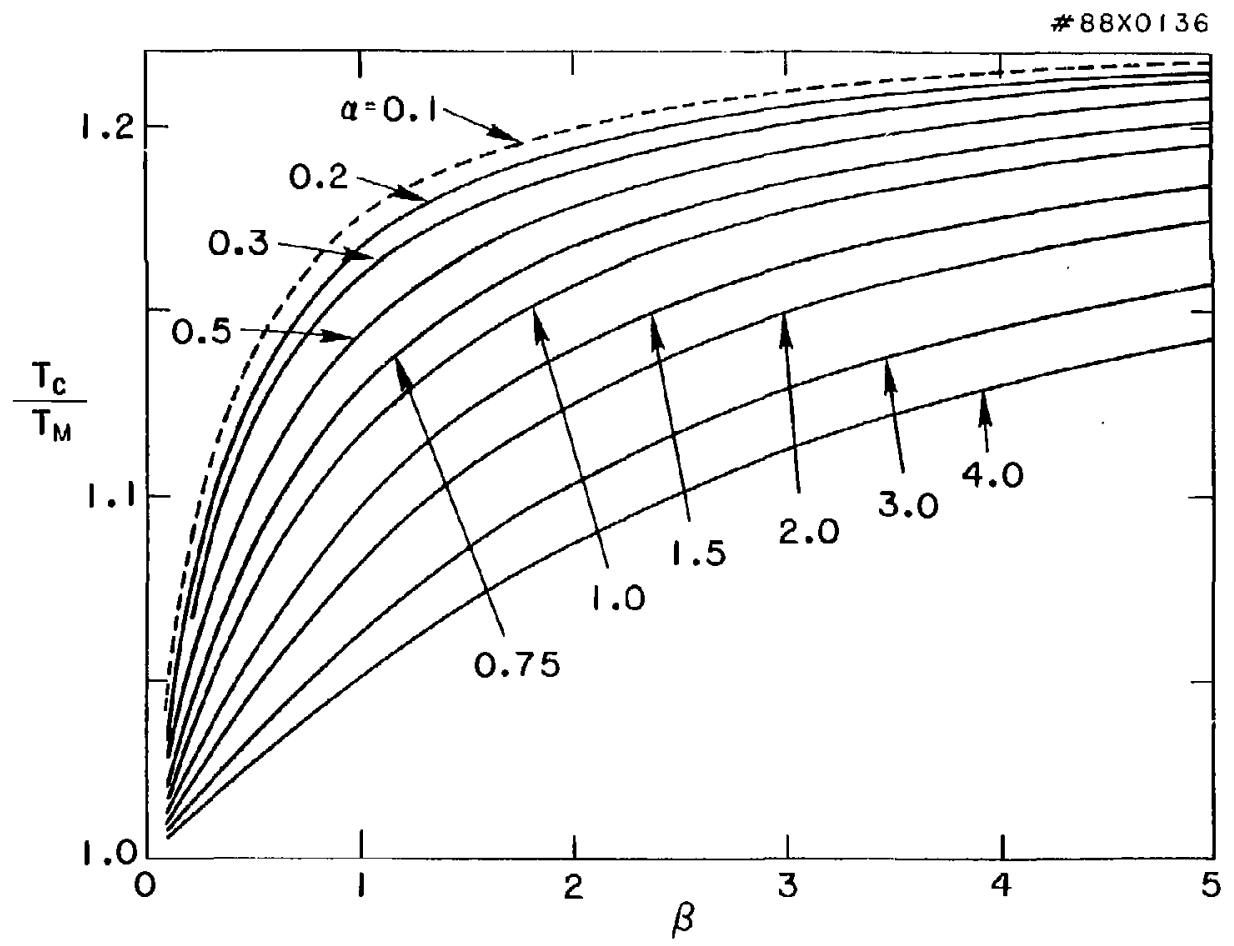

lig . 3 


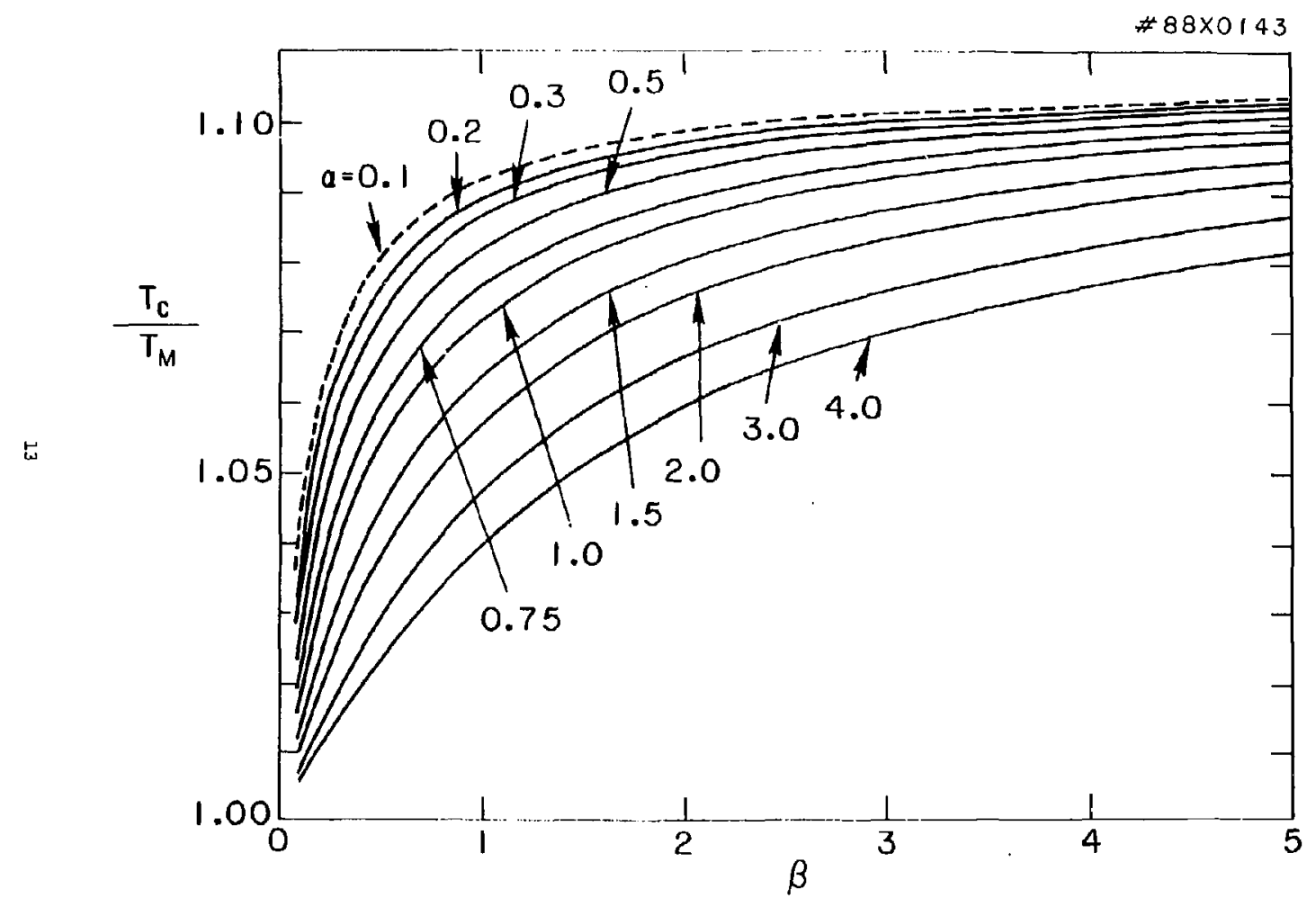

fig. 


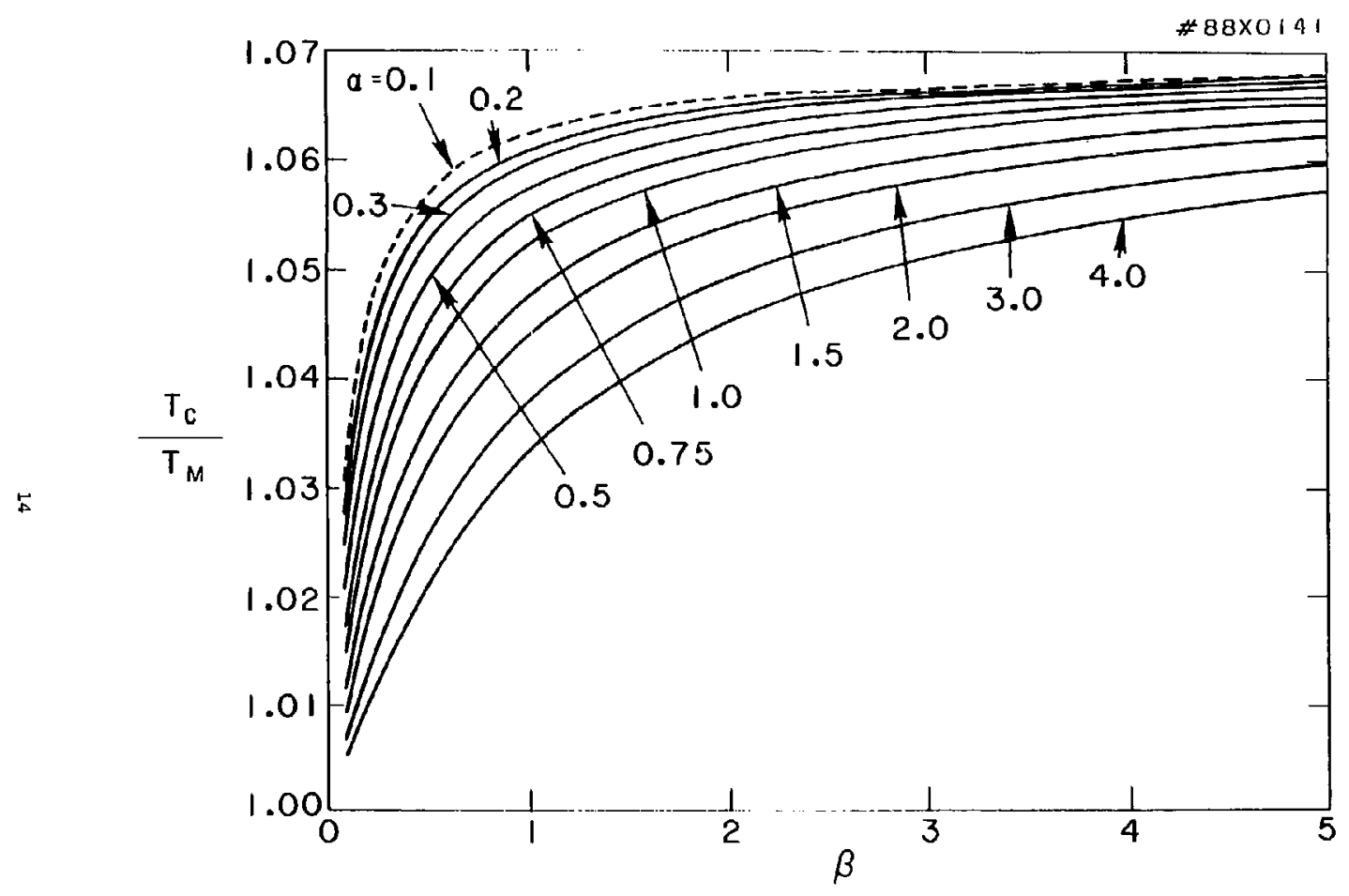

I. $i$ ). 
\#88x0139

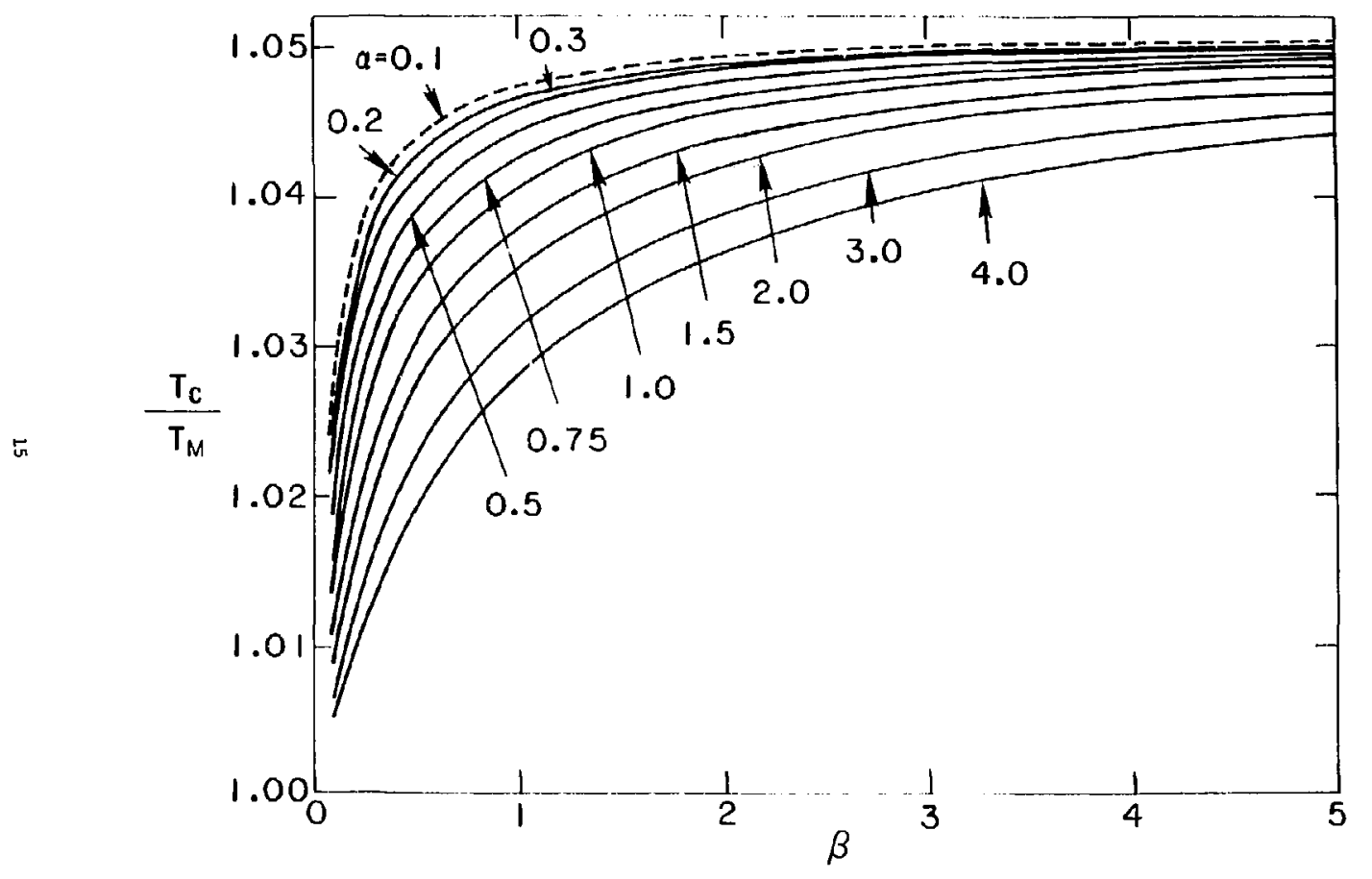


1380137

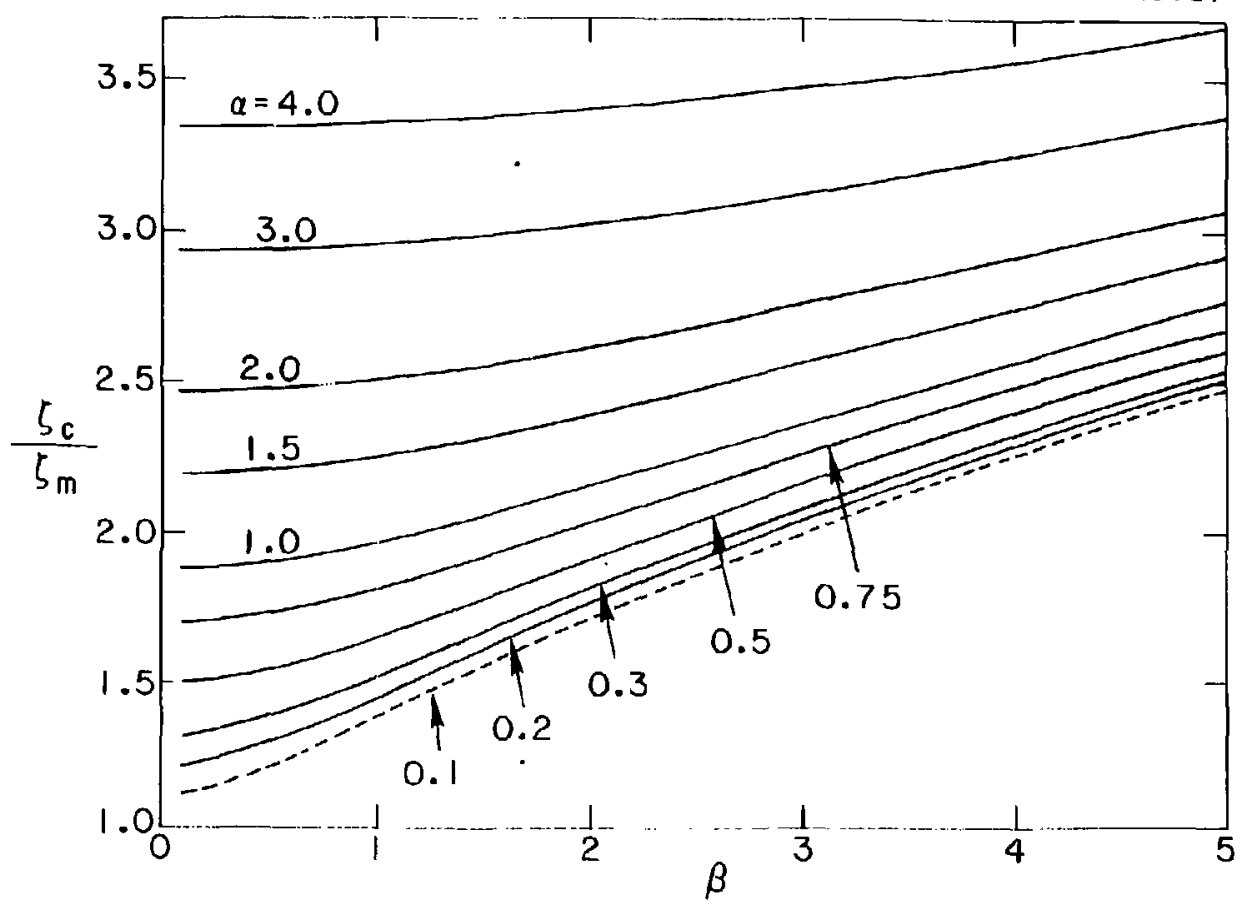

liig. : 


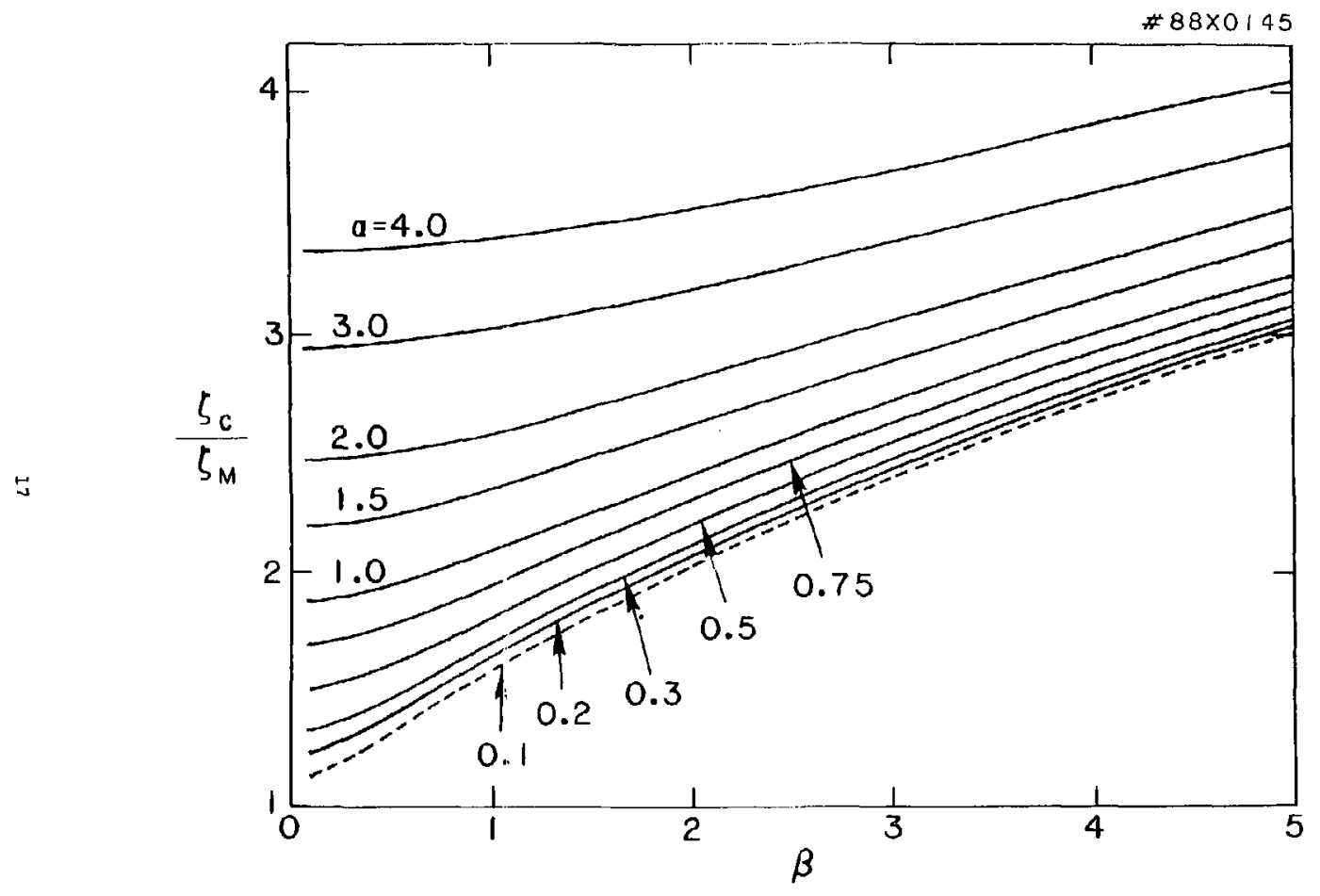


\#88x0140

备

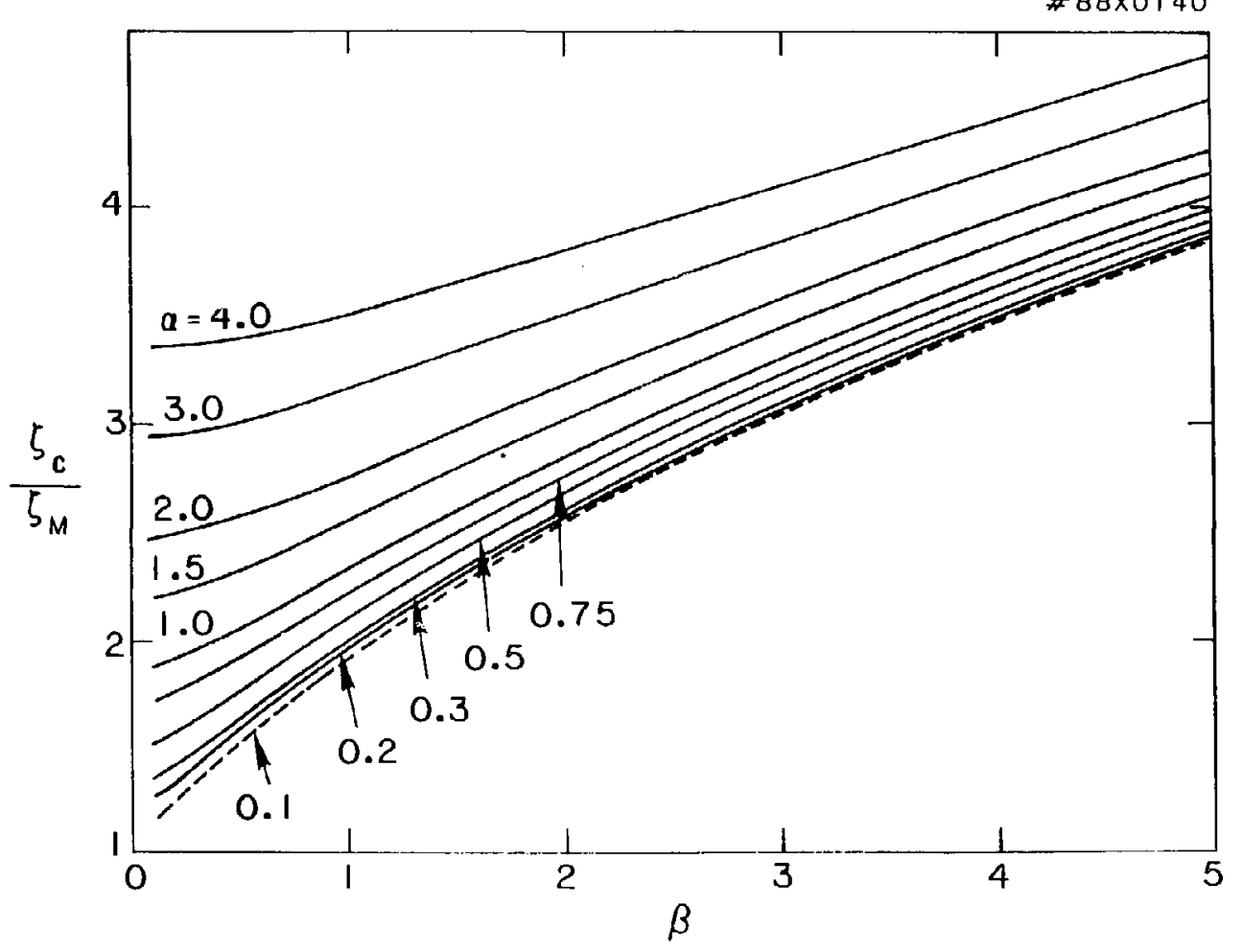

I.iu. is 


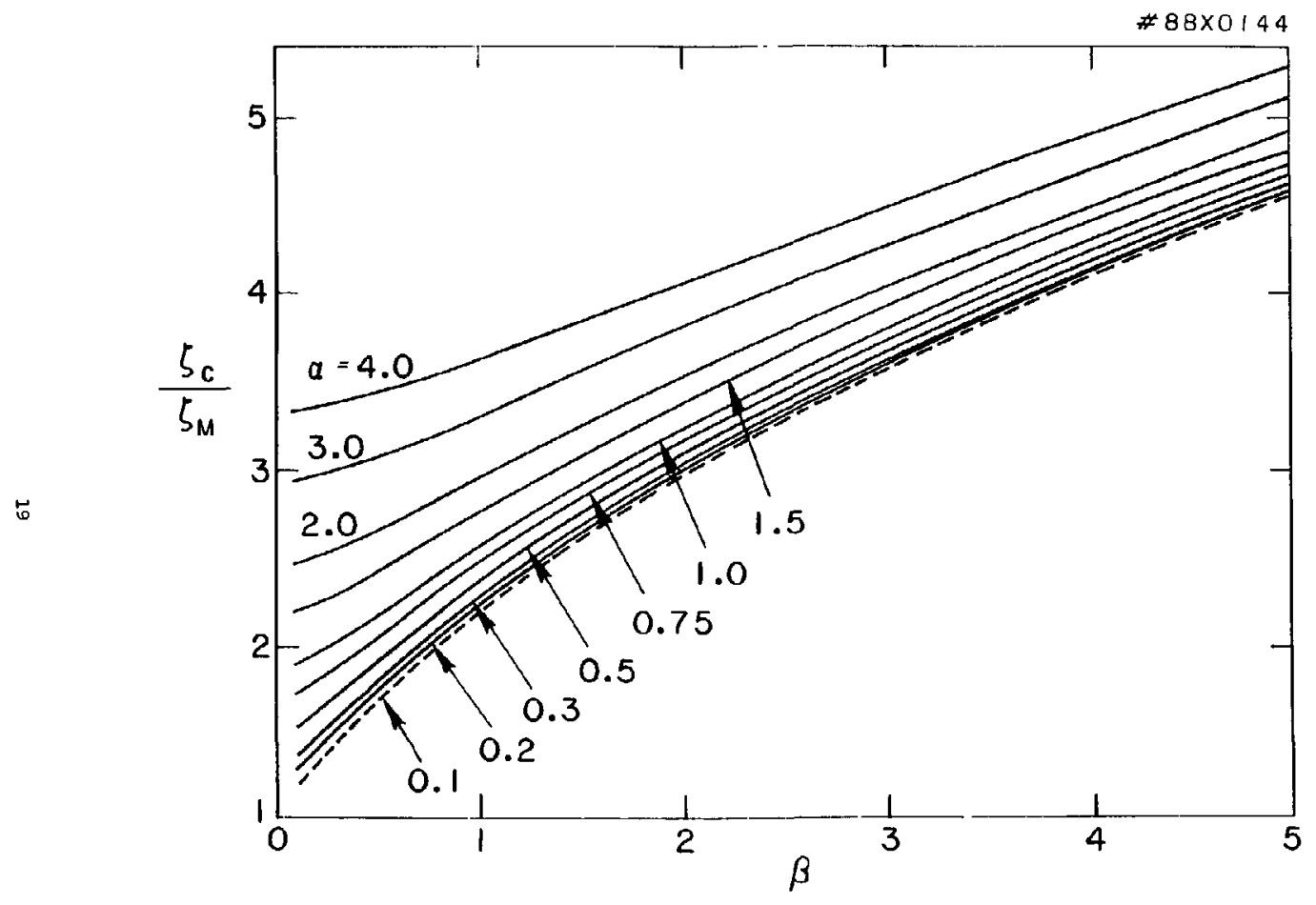




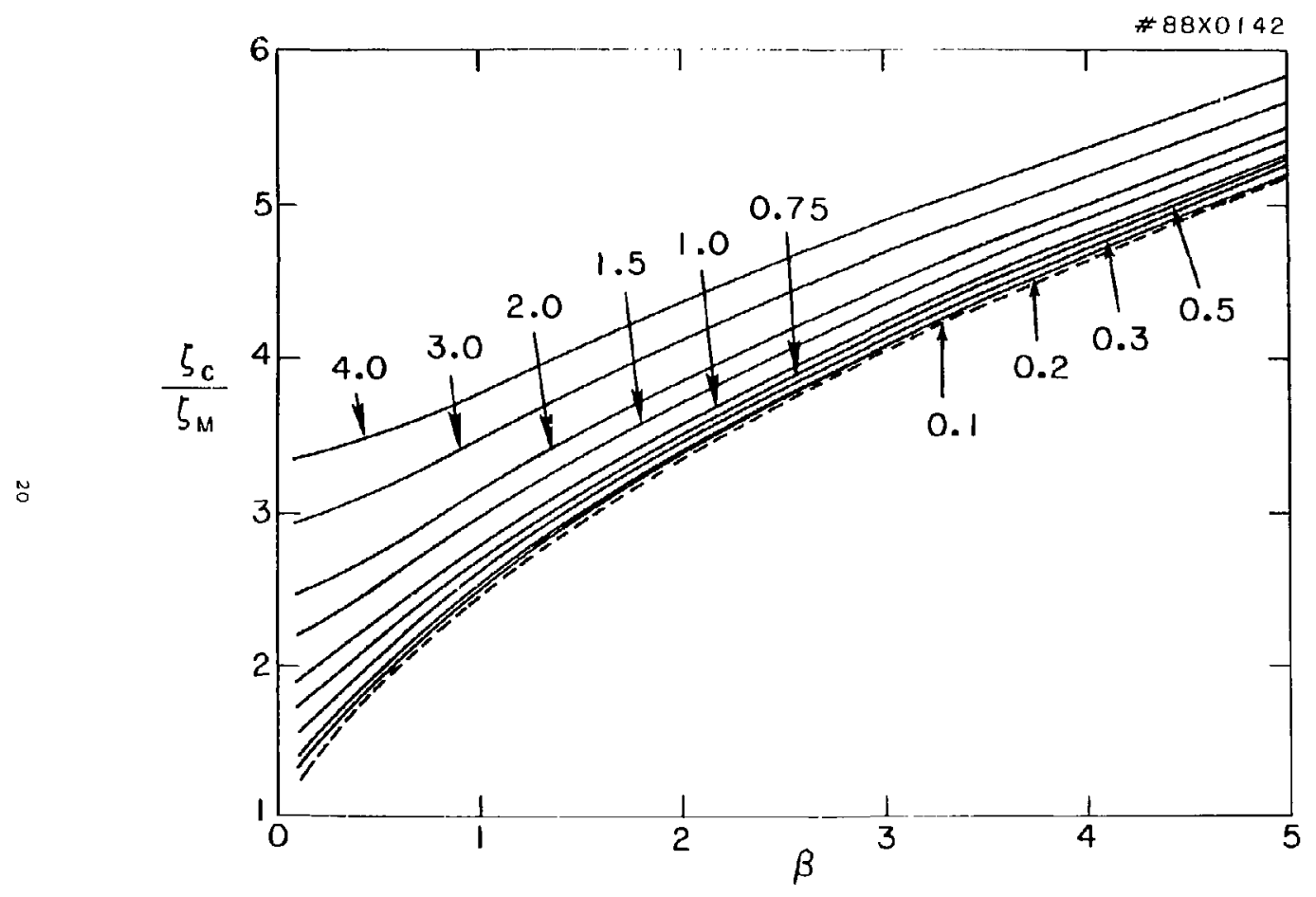

1'ily. II" 
\#88x0133

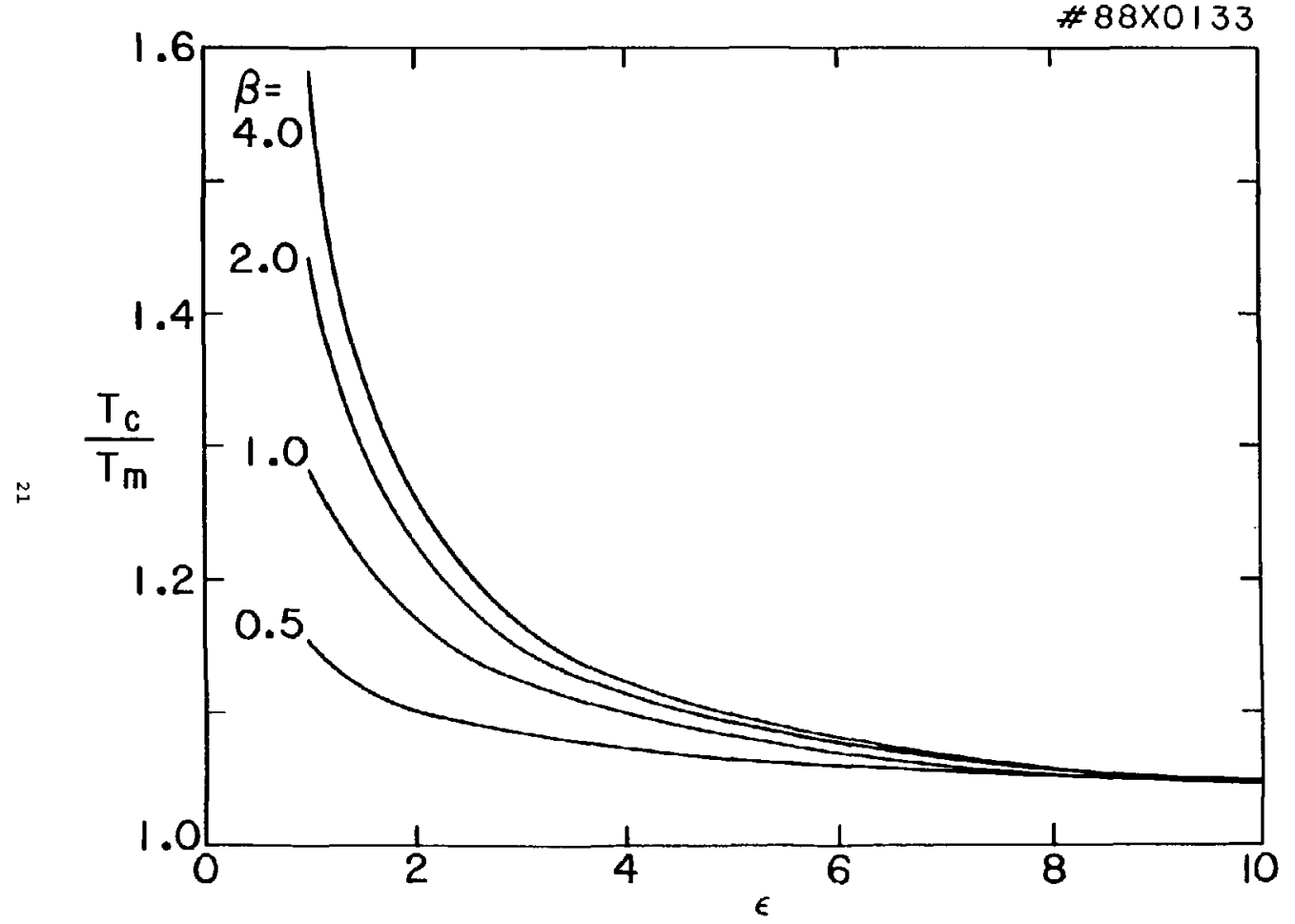

I.jug. 11 


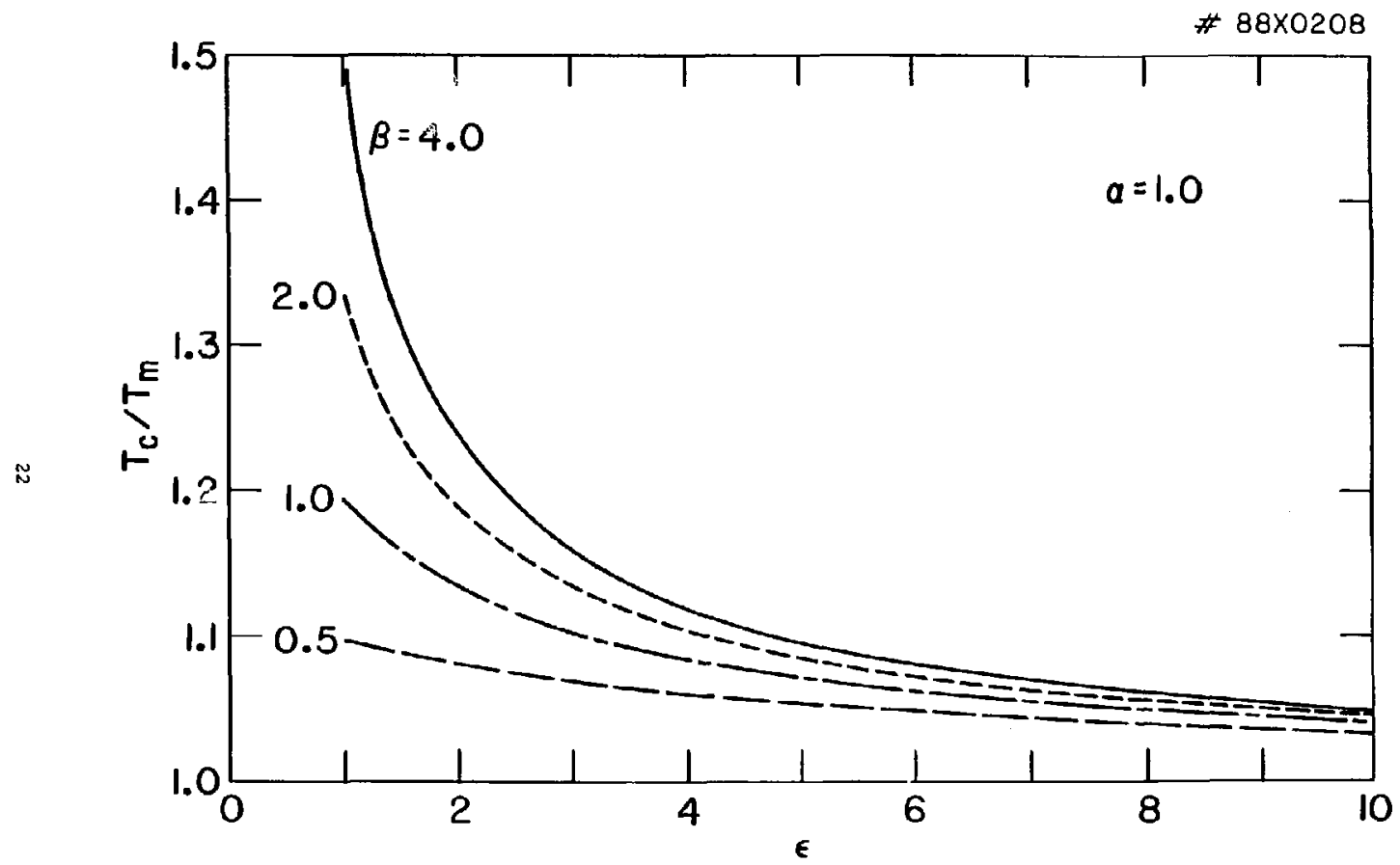

Pig. 12 


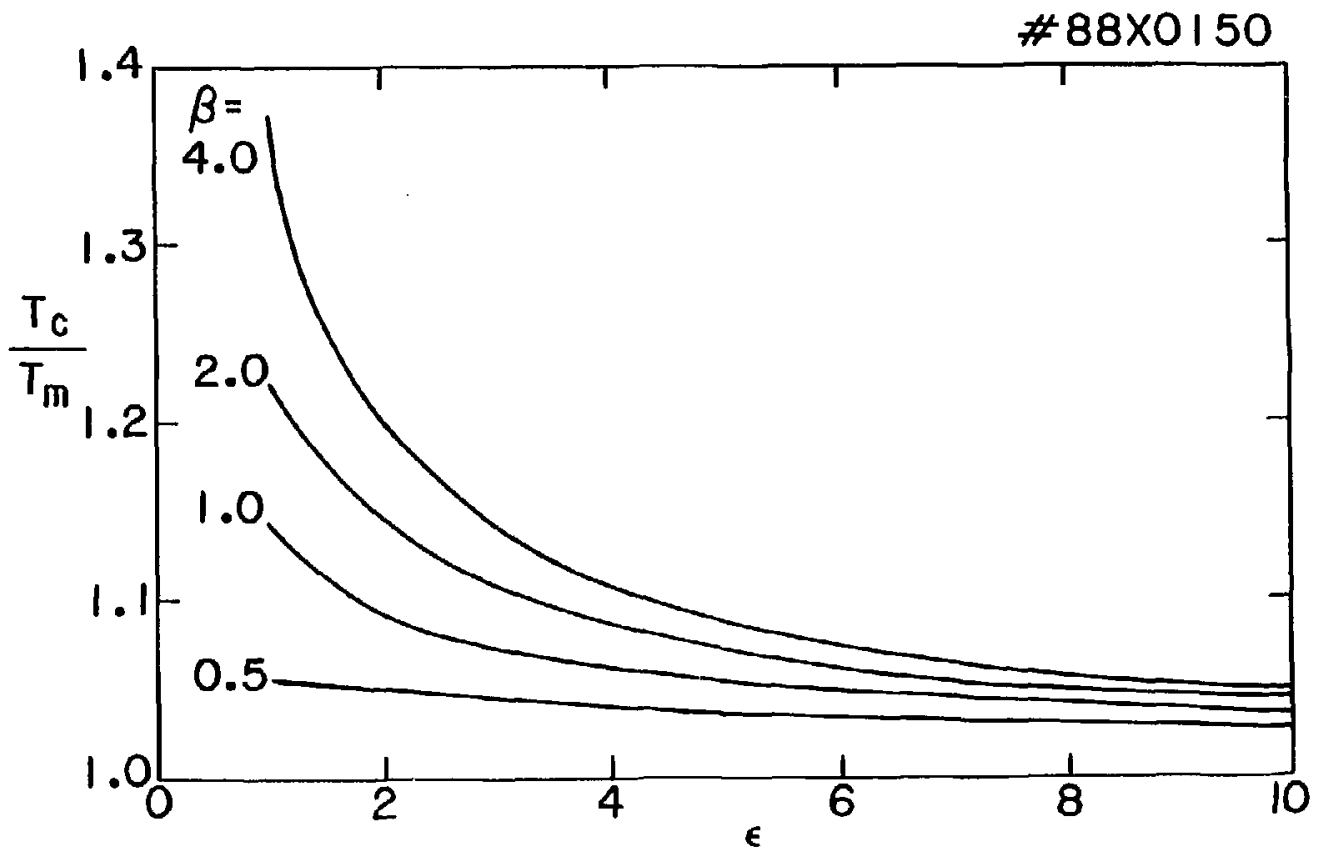

1.14. 13 
\#88x0149

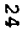

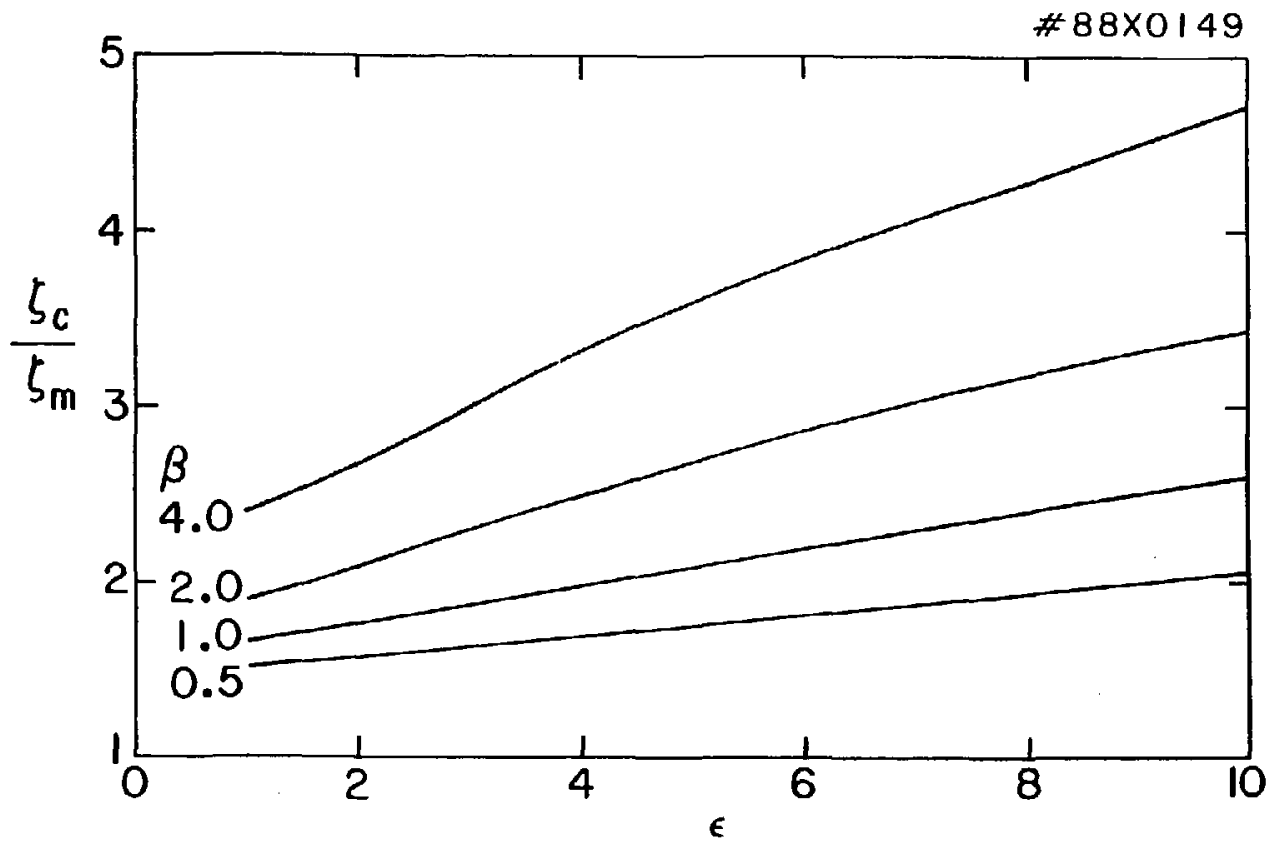

Fiy. 14 


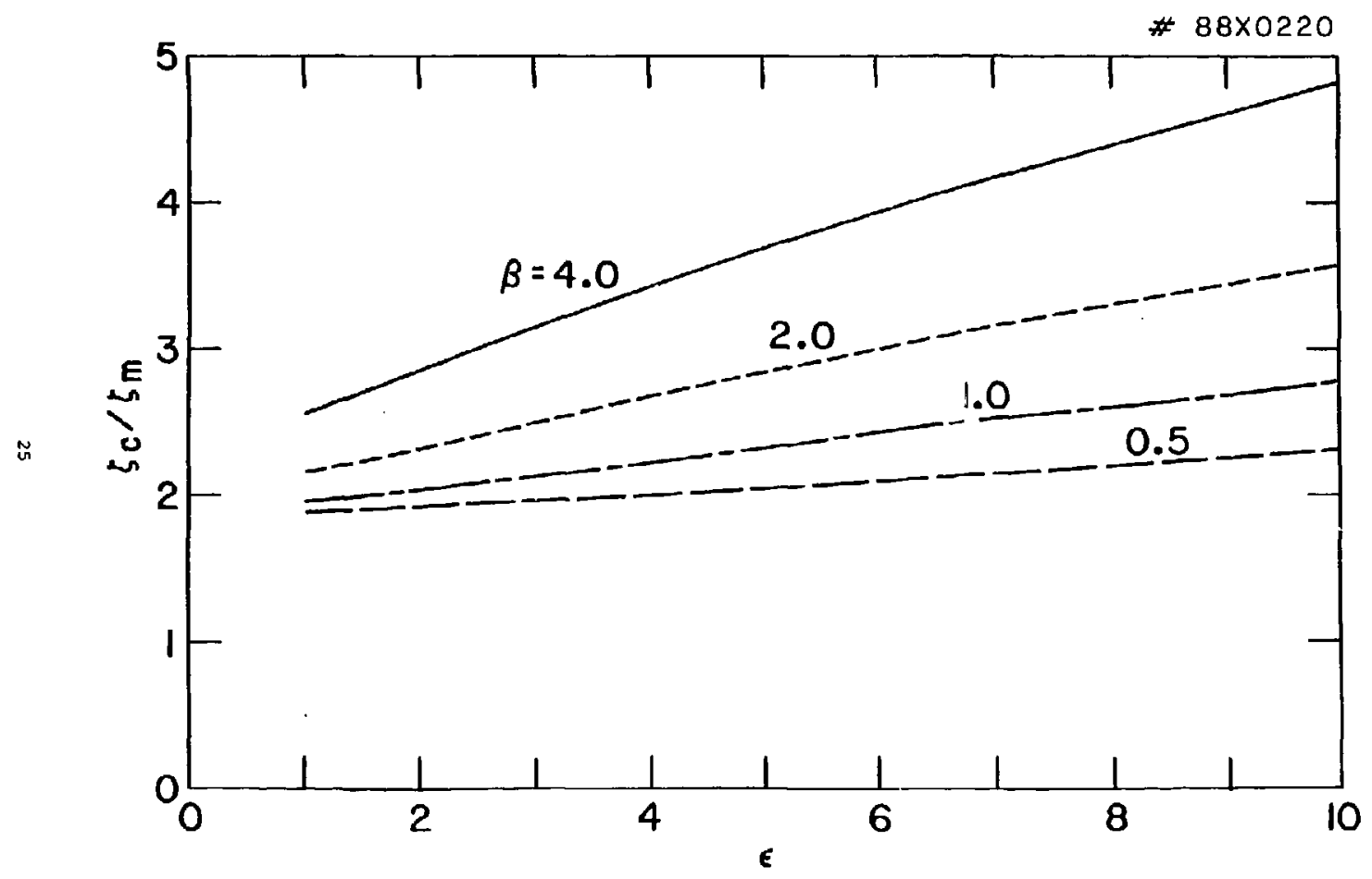




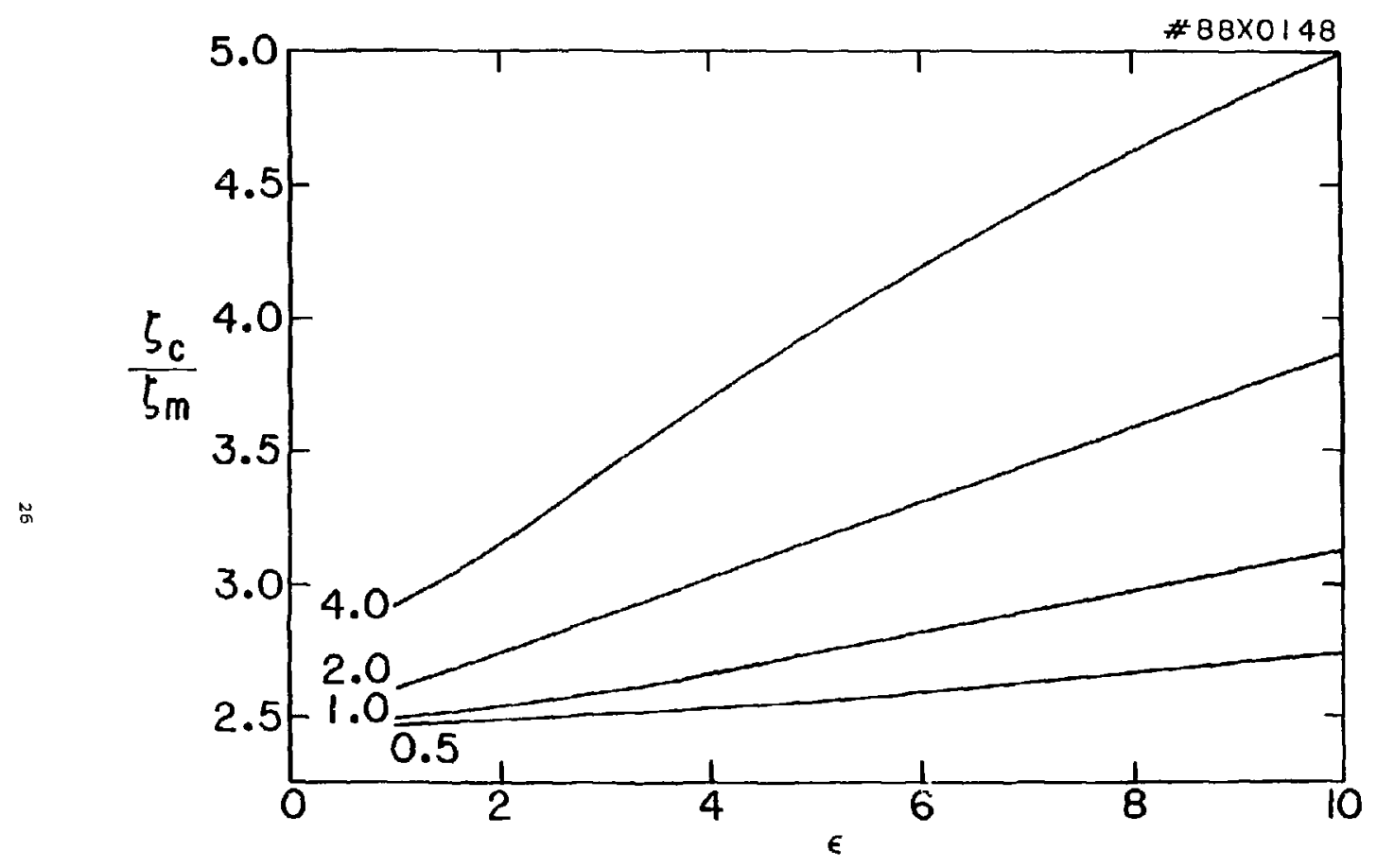

lib. If 


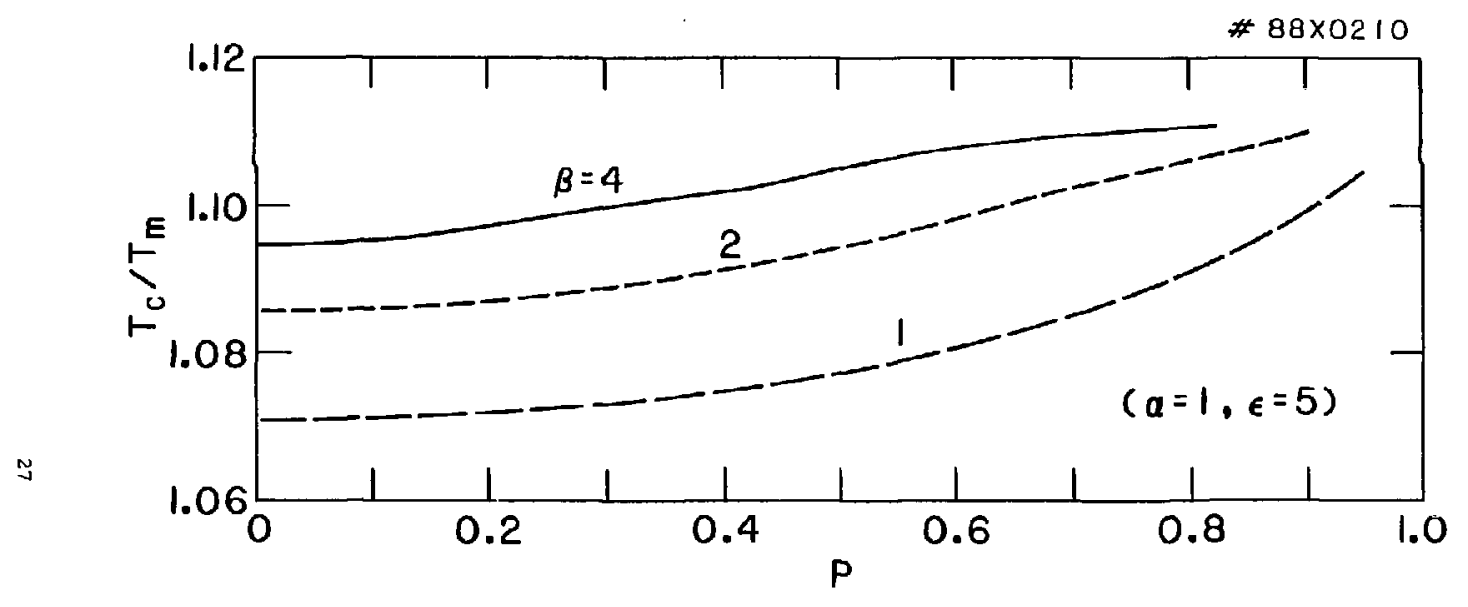

Fig. 17 


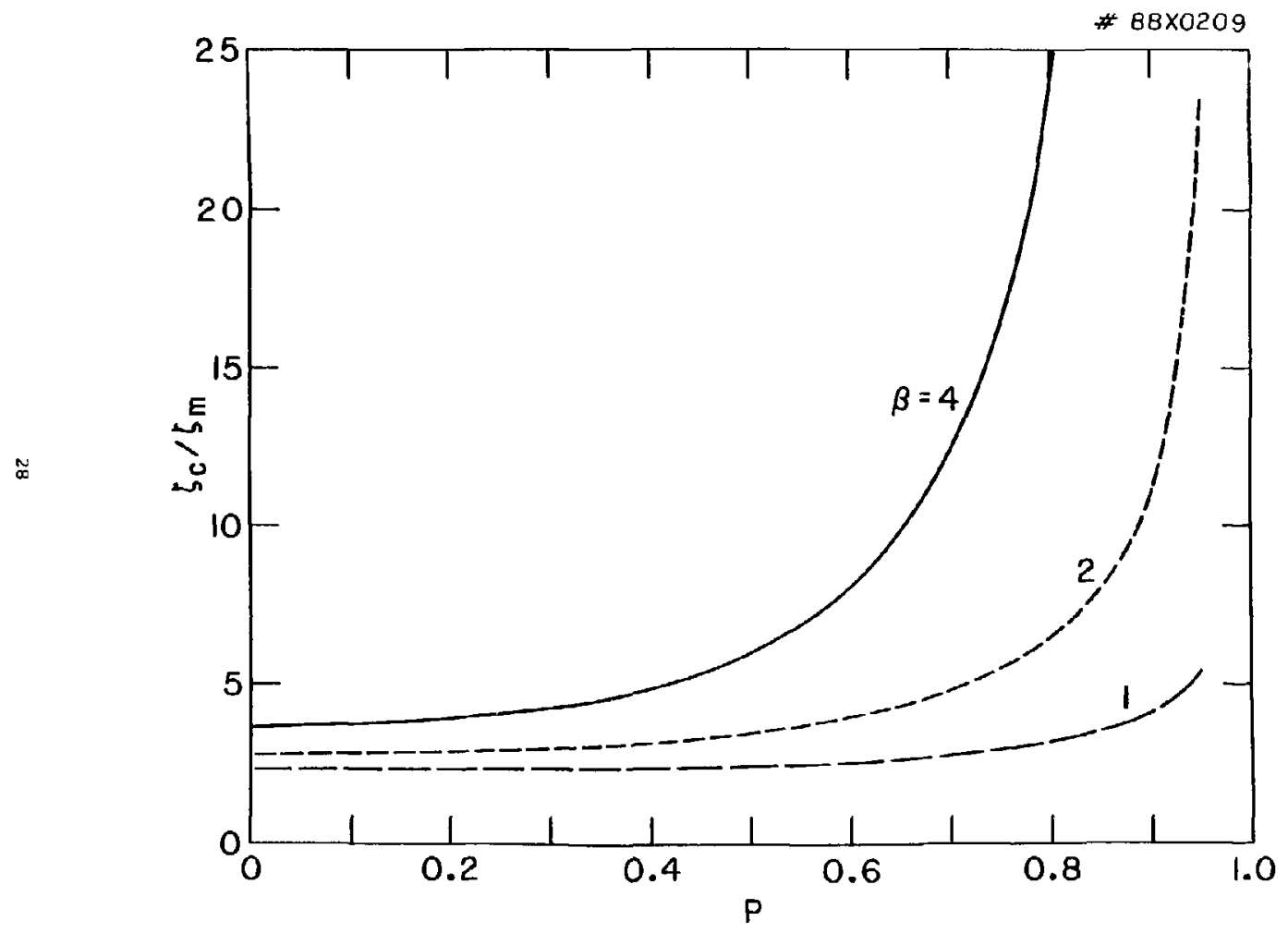

ficy- 1 : 


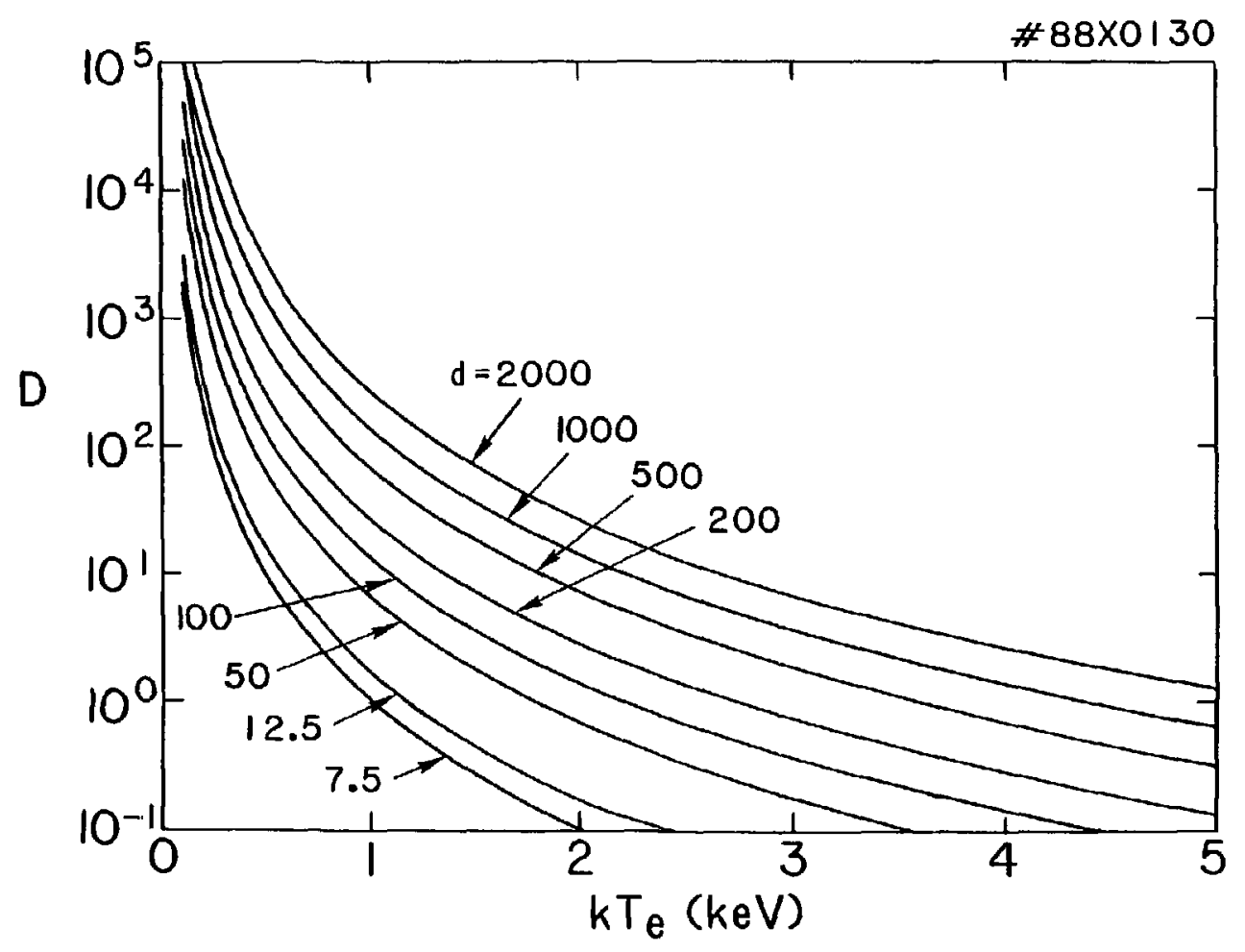


\#88X0129

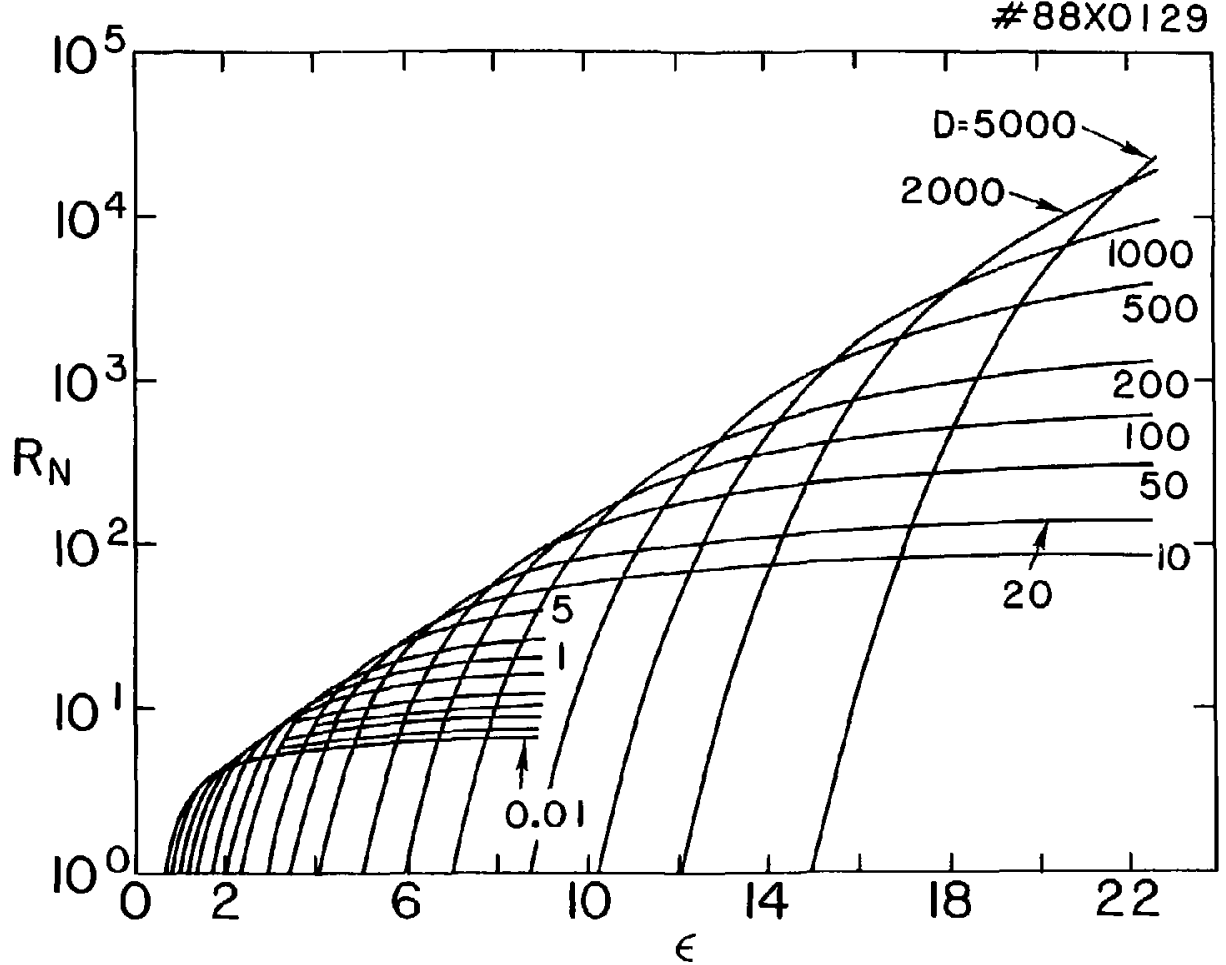




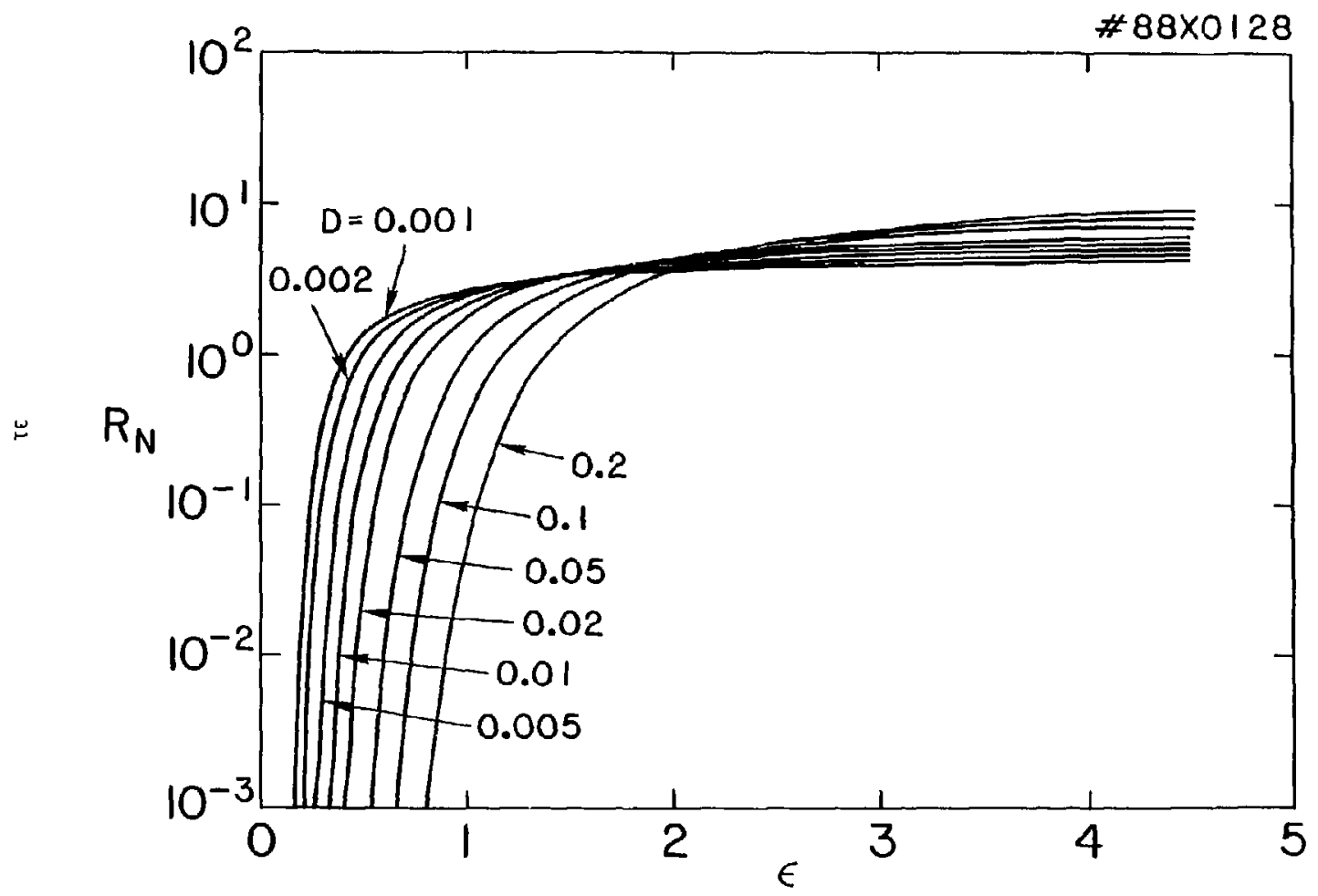




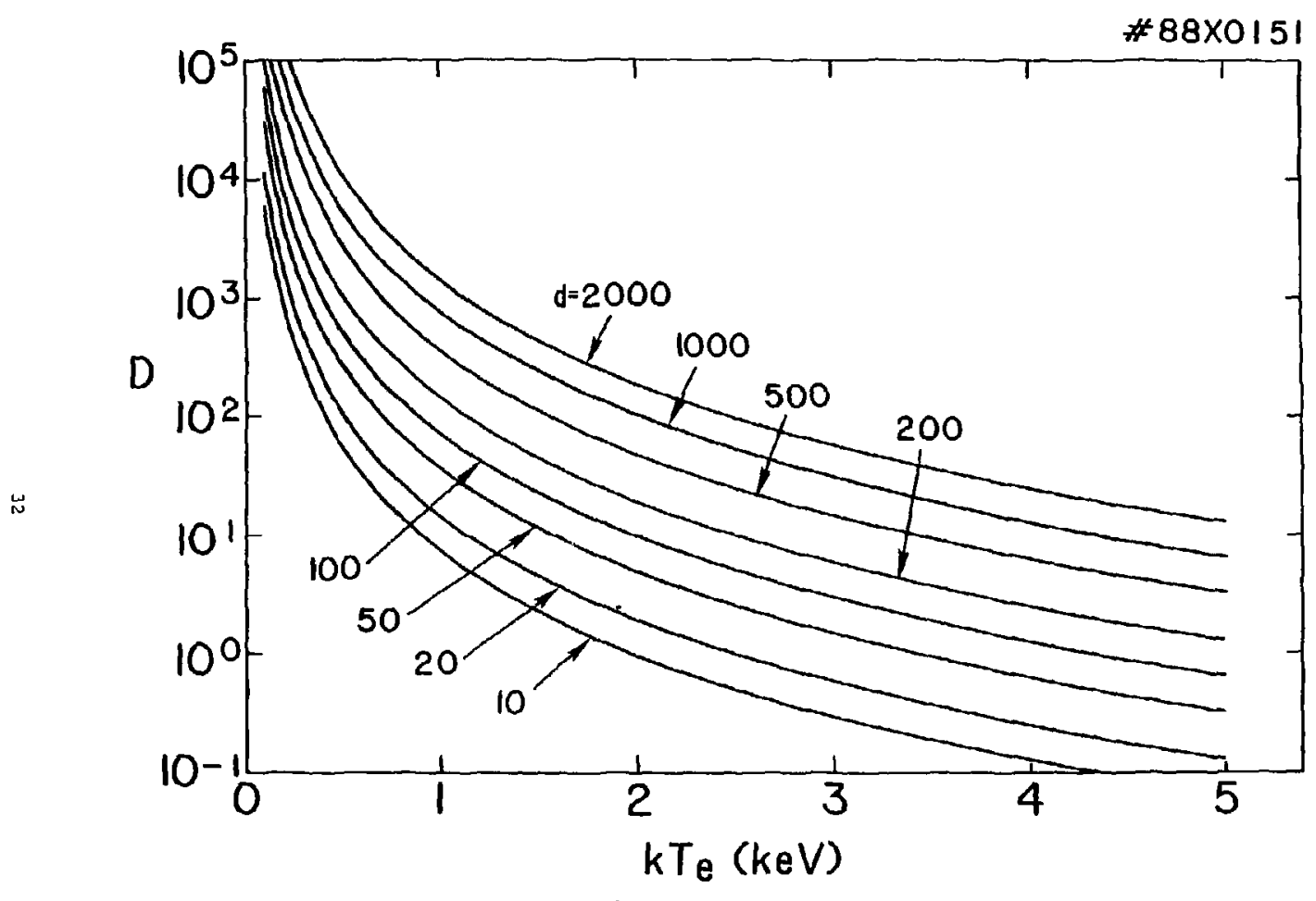

Fiy 12 


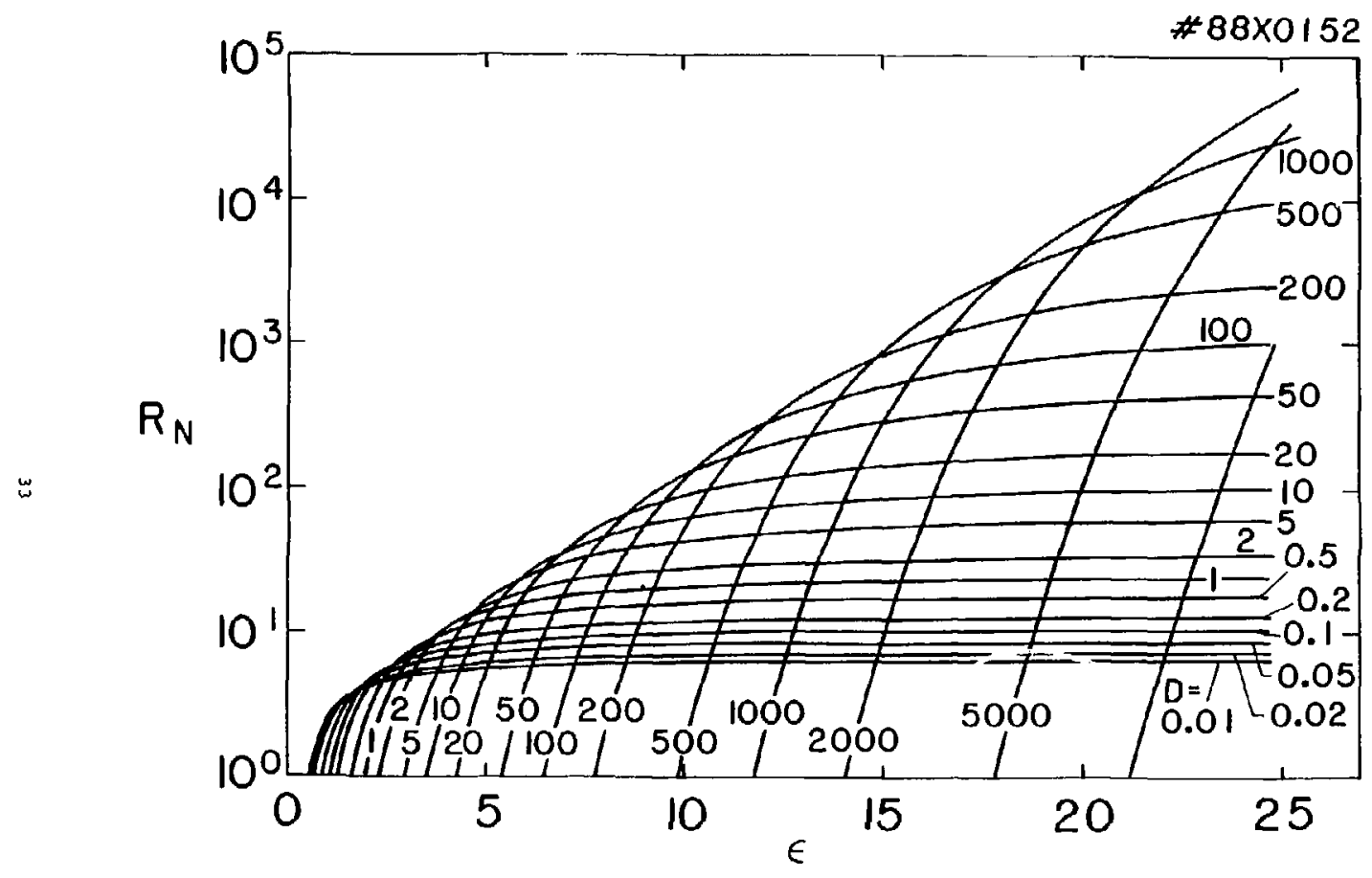


Or. Frank J. Paoloni, Univ of wollangong, AUSTRALIA Prof. M.H. Brennan, Univ Syaney, AustRALIA

PIasma Research Lab., Australian Nat. Univ.., AUSTRALIA

Prof. 1.R. Jones, Flinders Univ.. AUSTRALIA

Prof. F. Cap, Inst Theo Phys, AuSTRIA

Prof. M. Heindler, Institut fur Theoretisehe Physik, AuSTRIA

M. Goossens, Astronomisch Instituut, BELGIUM

Ecole Royale Militaire, Lab do Phys Plasmas, BELgIUM

Commission-European, Og-XII Fusion Prog, BELGIUM

Prof. R. Boucique, Laboratoriun voor Natuurkunde, BELGIUH

Or. P.H. Sakanaka, Instituto FIsica, BRAZIL

Instituto de Posquisas Espaciasi-INPE, BRAZIL

Documents oftice, Atomic Energy of Canada Limitad, CANADA

Dr. M.P. Bachynski, MPG Technologies, InC., CANADA

Or. H.M. Skarsgard, University of Saskatchewen, CANADA

Or. H. Garnard, University of gritish Columbia, CANADA

Prof. J. Teichmenn, Univ. of Montreal, CakhoA

Prot. 5.R. Sreqnivasan, University of Calgary, Camada

Prot. Tudor $H$. Jchnston, INRS-Energie, CankDa

DF. C.R. Jamos, Univ. of Alberta, CAMDA

Or. Peter Lukac, Komenskaho Univ, CZECHOSLOVAKIA

The Librarian, Culha Laboratory, ENGAMD

The Librarian, Rutherfard Appleton Laboratory, ENGLAND

Mrs. S.A. Hutchinson, JET Library. ENGLANo

C. Mouttet, Lab, de Physique des Hilieux Ionisés, FRANCE

J. Radot, CEN/CADARACHE - Bat 506, FRANCE

Univ. of loonnina, Library of Physics Dept. GREECE

DF. Tom Mual, Acadeny Bibliographic Ser., HONG Kong

Preprint Library, Hungorian Acadeay of Selences, MUNGARY

Dr. B. Dasgupta, Sana Inst of Nuel. Phys., IROIA

DF. P. Kaw, Institute for Pl asme Research, INOIA

Dr. Phil ip Rosenau, Israal Inst. Tech, ISRaEL

Librarian, Int'I Ctr Theo Phys, TTALY

Prof. G. Rostagni, Univ Di Padova, ITALY

Miss cletia De Palo, assoc EuRATOH-ENEA, ItAly

Giblioteca, instituto di Fisica del Plasma, ITALY

Dr. H. Yamato, Toshiba Ros d Dov, JAPAN

Prof, 1. Kawakami, Atonic Enorgy Ros. Institute, JAPAN

Pror, Kyoji Nishikawa, Univ of Hiroshima, JAPAN

Direc. Dept. Large Tokatak Res. JAERI, JAPAN

Prof. Satoshi Itoh, Xyushu University, JAPAN

Ressoarch Info Conter. Nagoya University, JAPAN

Prof, S. Tanaka, Kyoto University, JAPAN

Library, Kyoto Univorsity, JAPAN

Prot. Nobuyuki Inoue, University of Tokyo, JAPAN

S. Wor $i$, JAERI, JAPAN

- Librarian, Kores Advanced Energy Res. Institute, KOREA Prot, 0.1. Choi, Adv. Inst Sel \& Tech, KOAEA

Prof. A.S. Lilay, University of Waikato, NEW IEALAND

Institute of Plasma Physics, PEOPLE's REPUBLIC OF CHIN

Librarian, Institute of Phys., PEOPLE'S REPUBLIC OF CHINA

Library, Tsing Hua University, PEOPLE'S REPUBLIC OF CHINA
2. Li, Southwest inst. Physics, PEOPLE'S REPUBL IC OF OHINA Prof. J.A.C. Cabral, Inst Superior Teenico, PORTugal

Or, Octavian Patrus, AL I CUZA University, ROMANIA

Or. Johan de Villiers, fusion Studies, AEC, SO AFRICA

Prat. M.A. Helluerg, University of Matal, SO AFRICA

C.I .E.M.A.T., Fusion Div. Library, SPAIN

Or. Lennart Stont to, University of UMEA, SWEDEN

Library, Royal Inst Tech, SWEDEN

Praf. Hans Wilhelmson, Chalmars Univ Tach, SWEDEN

Centre Phys das Plasmas, Ecole Polytech Fed, SWITZERLANo

Bibliotheek, Fom-Inst Voor Plasma-fysica, THE NETHERLANOS

Dr. 0.D. Ryutov, Siberlan Acad Sci, USSR

Dr. G.A. El iseev, Kurchatov Institute, USSR

Dr. V.A. Glukhikh, Inst Electrophysical Apporatus, USSR

Or. Y.T. Tolok, Inst. Phys. Tech. USSR

Or. L.M. Kovriztnnykh, Institute Gen. Physics, USSR

Nuclear Res. Estaol ismment, Jul ich Lto., H. GepananY

Bibliathok, Inst. Fur Piasmaforschung, W, GERMANY

Or. K. Schindler, Ruhr Universitat Bochum, W. GERMany

ASDEX Reoding Ran, IPP/Max-PI anck-institut $f$ ur

Plasnaphysik. H. GERMANY

Librarian, Max-Planck Institut, 'W. GEPMANY

Prof. R.K. Janev, Inst Phys, YUgosLAVIA 